\title{
Augmentation Cystoplasty: in Pretransplant Recepients
}

\author{
Ashraf Abou-Elela \\ Cairo University, \\ Egypt
}

\section{Introduction}

Augmentation cystoplasty is performed to increase bladder capacity and compliance. The primary use of augmentation cystoplasty is to protect renal function, to achieve urinary continence, and often to facilitate urinary tract reconstruction (1). The most common problems necessitating bladder augmentation are neurogenic bladder dysfunction secondary to myelodysplasia, extrophy of the bladder, and posterior urethral valves. However, many other conditions may require bladder augmentation including tuberculosis, interstitial cystitis, multiple surgeries, chemotherapy and radiation therapy.

Not all patients undergoing augmentation cystoplasty, especially in the pediatric population, can achieve complete emptying of their bladder by spontaneous voiding. It was the success and wide spread acceptance of clean intermittent catheterization (CIC) in the mid-1970s that made augmentation cystoplasty and continent urinary diversion possible especially in children (2).

Conventional enterocystoplasty employs the use of detubularized segments of small or large bowel. Ileum, sigmoid and cecum have all been used; several studies have confirmed the reliability of these segments $(3,4)$.

Despite the functional success of enterocystoplasty, clinical experience has demonstrated that there are numerous complications that can result from the incorporation of small and large bowel and their heterotropic epithelium into the urinary tract. To avoid some of the deleterious side effects of enterocystoplasty, several procedures have been developed to augment the bladder without the use of the bowel. These include gastrocystoplasty, the use of dilated ureter (either naturally dilated or balloon dilated), autoaugmentation and seromuscular enterocystoplasty $(5,6,7,8,9)$.

Autoaugmentation involves the excision of the detrusor muscle from the dome of the bladder allowing the epithelium to form a large diverticulum which may or may not be covered with a seromuscular gastric or sigmoid patch as a backing. In addition, recent advances in tissue engineering substrates and biomaterials have enhanced our abilities to possibly regenerate bladder tissue that is clinically useful for augmentation purposes. Generally, three classes of biomaterials have been used for engineering of genitourinary tissues; naturally derived materials, such as collagen and alginate, cellular tissue matrices such as bladder and small intestinal submucosa (SIS) and synthetic polymers such as polyglycolic acid (PGA) and polylactic acid (PLA) (10,11,12, 13). 
At this time, even so, there are significant potential problems with the use intestinal segments in the lower urinary tract; gastrointestinal (GI) segments remain the gold standard for increasing bladder capacity and improving compliance. These problems include: hyperchloremic metabolic acidosis, hyokalemia, hypocalcemia, ammoniagenic encephalopathy, bone demineralization, vitamin $\mathrm{B}_{12}$ deficiency, malabsorption, drug absorption toxicities, growth retardation, mucus secretion, urinary tract infection, urinary calculi and tumor formation. Gastrocystoplasty may be complicated with hypochloremic metabolic alkalosis and hematuria-dysuria syndrome (14).

Therefore augmentation cystoplasty should be offered only after medical intervention such as anticholinergic medications and intermittent catheterization fail to achieve dryness or to improve bladder compliance sufficiently.

The majority of children who undergo augmentation cystoplasty will require intermittent catheterization (1). The commitment and capacity of both child and the family to comply with catheterization must be assessed carefully. All potential complications should be discussed in details with adult patients and with the family of the child.

\section{Conditions that may require bladder augmentation}

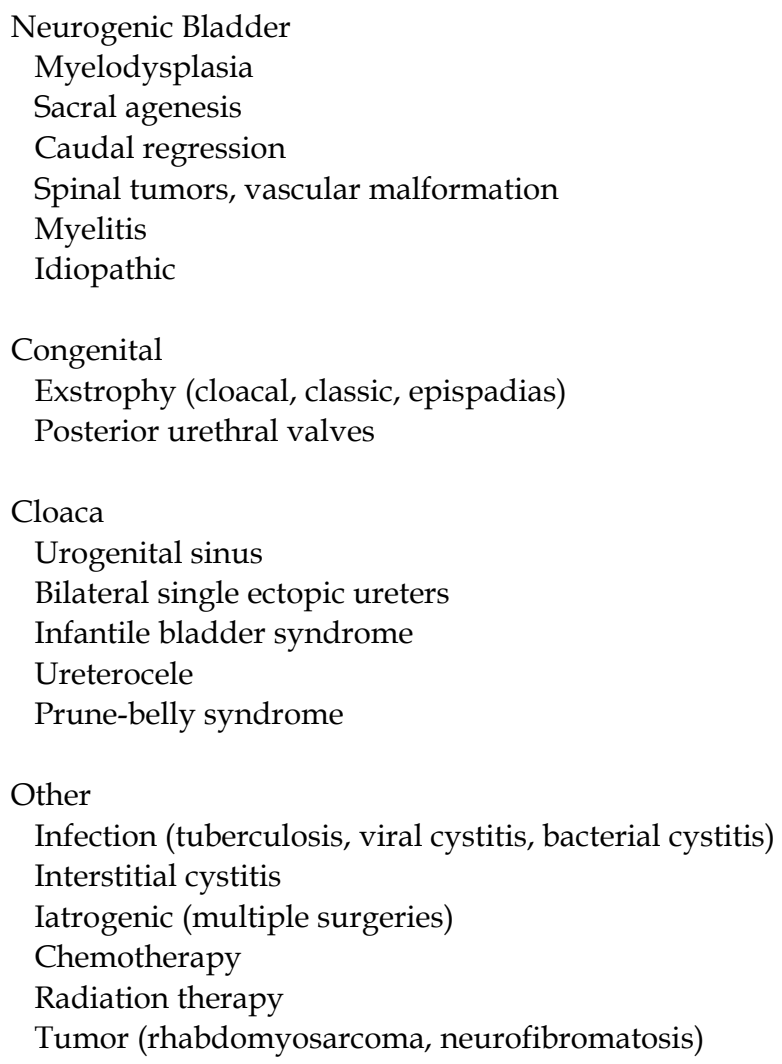




\section{Augmentation cystoplasty using bowel segments (enteroplasty)}

\subsection{General principles}

The initial approach to augmentation cystoplasty is similar regardless of the bowel segments to be used. Cystoscopy should be performed preoperatively to avoid any unsuspected anatomic abnormalities that may affect the surgery. In augmentation cystoplasty, the two critical aspects of the surgery are the preparation of the bladder and the augmentation segment chosen.

\subsection{Preparation of the native bladder}

In augmentation cystoplasty, the bladder usually is addressed first. Most commonly, a midline incision is used to expose the abdomen \& pelvis. If possible, the peritoneum is not entered until the bladder has been prepared for augmentation and other associated procedures such as ureteral reimplantation or bladder neck reconstruction have been performed. This minimizes third space fluid loss. The bladder is then bivalved through a sagittal incision from near the bladder neck anteriorly to near the trigone posteriorly, thus forming a "clam-shell" configuration. This maneuver is extremely important because the bladder must be opened fully to prevent the augmentation segment from acting as a diverticulum with the formation of an "hour-glass" deformity. Such an incision allows a technically easier anastomosis of the bowel segment and leaves the native bladder wings to add to the overall capacity. The bladder wings may also be used for implantation of a continent catheterizable channel (e.g. Mitrofanoff) or ureteral reimplantation.

Supratrigonal cystectomy is generally not recommended. The remaining cuff of the bladder is a relatively small area for anastomosis to the intestinal segment; therefore most of the bowel is approximated to itself which could result in the augmentation segment behaving as a diverticulum $(1,15)$. Nevertheless, other surgeons have recommended that the majority of the "diseased" bladder be excised in preparation for augmentation. A greater circumference for the anastomosis can sometimes be provided by opening the bladder in a stellate fashion with a second transverse incision into the two bladder halves (15).

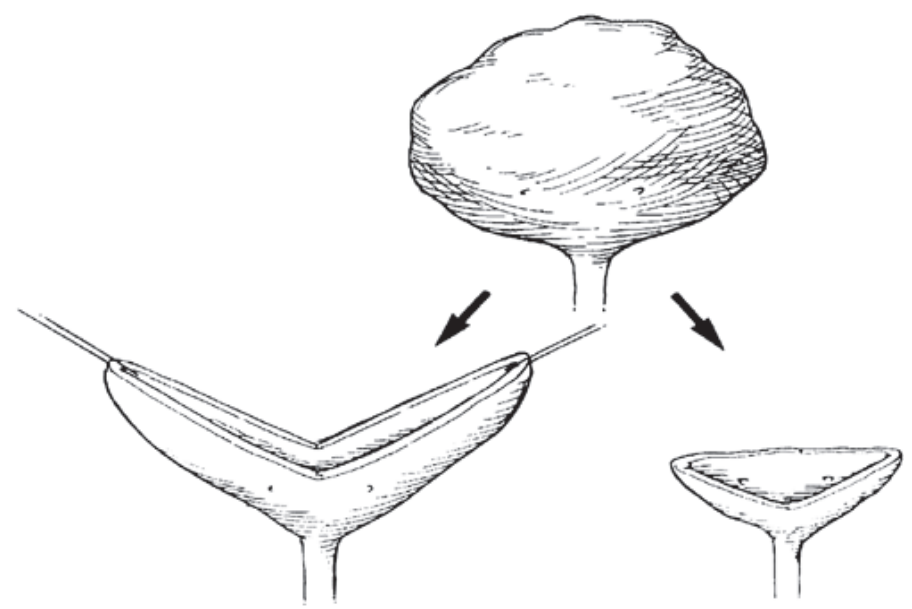

The dysfunctional bladder is opened in the sagittal plane from the bladder neck to the trigone ${ }^{(1)}$. 


\subsection{Harvesting the augmentation segment}

The size and configuration of the augmentation segment are probably more important than the type of bowel used.

Hinman (1988) and Koff (1988) have clearly demonstrated the advantages of opening bowel segments on their antimesenteric border, thereby allowing detubularization and reconfiguration of these segments. Detubularization and reconfiguration maximizes the added surface area to the bladder and thus the benefit of a given segment. Furthermore, the intrinsic innervation is disrupted and peristalsis is decreased significantly $(16,17)$.

Reconfiguration into a spherical shape provides multiple advantages that improve the overall capacity and compliance. Spherical configuration, by geometry, maximizes the volume achieved for a given bladder wall area. In addition, the spherical configuration also maximizes the radius of curvature, thereby increasing surface tension for a given bladder pressure, which tends to lead to further bladder expansion. This is the relationship of Laplace's law $(\mathrm{T}=\mathrm{k} \mathrm{RP})$, where $\mathrm{T}$ is wall tension, $\mathrm{k}$ is a constant dependant on elasticity and wall characteristics, $\mathrm{R}$ is the radius of curvature, and $\mathrm{P}$ is the luminal pressure.

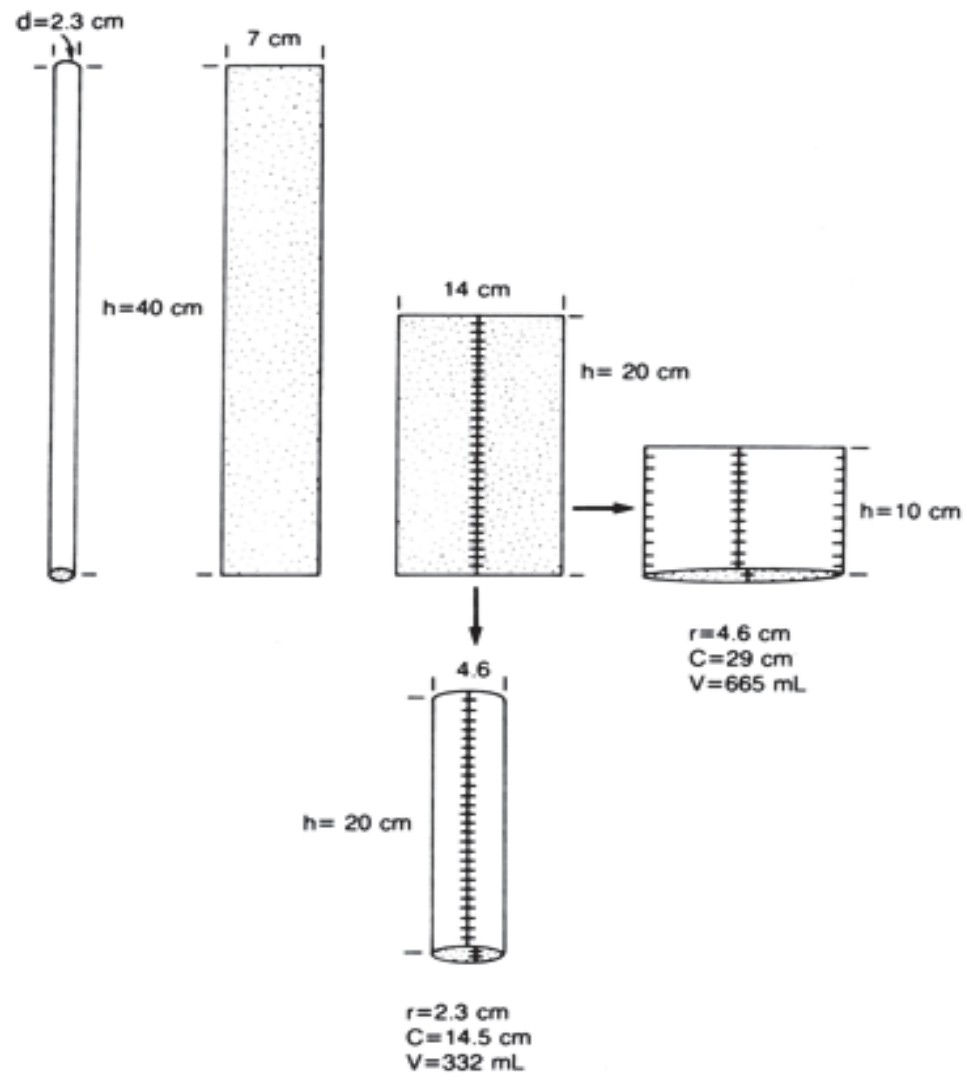

Calculated capacity of $40-\mathrm{cm}$ segment opened and folded twice is $665 \mathrm{~mL}$. C, circumference; $\mathrm{d}$, diameter; h, height; r, radius; V, volume. (From Hinman F Jr. Selection of intestinal segments for bladder substitution: physiological characteristics. J Urol 1988;139:521) 
The length of the segment used depends on: a) the radius of the bowel used; therefore a larger segment of small bowel usually is required; b) patient's age; c)the size of the pelvis; d) the volume of the native bladder being augmented; if the cystoplasty is being done on a bladder of moderate volume that generates high pressure by uninhibited contractions, less bowel is necessary than for a bladder that is tiny in capacity; e) patient's urinary volumes; patients with upper tract damage, particularly with concentrating ability, may make huge volumes of urine and require a larger capacity.

Depending on the volume needed, 15 to $40 \mathrm{~cm}$ of ileum and approximately $20 \mathrm{~cm}$ of colon is usually used for cystoplasty. If a segment of stomach is to be used as the augmentation segment, a wedge of at least one-third of the stomach is harvested (19). The gastric wedge requires no reconfiguration as it fits well onto the bivalved bladder. If the ureter is to be used as an augmentation segment, there must be significant dilation and it should likewise be detubularized before being anastomosed to the bladder (20).

The choice of the augmentation segment needs to be tailored individually to each patient. For example, patients with a short ileal mesentery may require the use of the sigmoid to allow for a tension-free anastomosis. Patients with a short gut, renal insufficiency, or a history of pelvic radiation may be better served with a gastrocystoplasty. Patients with myelomeningocele or imperforate anus theoretically could develop diarrhea if the ileocecal valve is taken from their gastrointestinal (GI) tract (21, 22). Other factors to consider include the need for ureteral reimplantation and the need for a continent catheterizable channel. Therefore, it is important to consider each patient individually when selecting the appropriate augmentation segment.

\begin{tabular}{|c|c|c|c|c|c|c|c|c|}
\hline Cystoplasty & Mean & Mean & Mean & $\begin{array}{l}\text { Mean } \\
\text { Value }\end{array}$ & $\begin{array}{c}\text { First } \\
\text { Contraction }\end{array}$ & $\begin{array}{c}\text { Max. } \\
\text { Contraction }\end{array}$ & & \\
\hline & $\begin{array}{l}\text { Age } \\
(\mathrm{yr})\end{array}$ & $\begin{array}{l}\mathrm{F} / \mathrm{U} \\
(\mathrm{mo})\end{array}$ & $\begin{array}{l}\text { Cap } \\
(\mathrm{mL})\end{array}$ & $\begin{array}{c}\text { At } 300 \\
\text { mL cm } \\
\mathrm{H}_{2} \mathrm{O}\end{array}$ & $\begin{array}{l}\text { Mean Vol } \\
\quad(\mathrm{mL})\end{array}$ & $\begin{array}{c}\text { Mean } \mathrm{P} \mathrm{cm} \\
\mathrm{H}_{2} \mathrm{O}\end{array}$ & $\begin{array}{c}\text { Mean } \\
\text { Vol } \\
(\mathrm{mL})\end{array}$ & $\begin{array}{l}\text { Mean } \\
\mathrm{P} \mathrm{cm} \\
\mathrm{H}_{2} \mathrm{O}\end{array}$ \\
\hline $\begin{array}{l}\text { Tubular right } \\
\text { colon }\end{array}$ & 17.5 & 9.7 & 630 & 18.6 & 139 & 37 & 467 & 63 \\
\hline $\begin{array}{l}\text { Detubularized } \\
\text { right colon }\end{array}$ & 28.5 & 5.1 & 641 & 9.4 & 329 & 24 & 596 & 42 \\
\hline Tubular ileum & 66.8 & 7.0 & 311 & 36 & 110 & 60 & 218 & 81 \\
\hline $\begin{array}{l}\text { Detubularized } \\
\text { ileum }\end{array}$ & 20.0 & 5.7 & 403 & 14.4 & 197 & 22 & 265 & 28 \\
\hline
\end{tabular}

From Goldwasser B, et al. Cystometric properties of ileum and right colon after bladder augmentation, substitution or replacement. J Urol 1997; 138(2):1007.

Effect of detubularization of colon and ileum on cystoplasty compliance and contraction

\section{Types and techniques of enterocystoplasty}

\section{1 lleocystoplasty}

\subsubsection{Technical considerations}

Goodwin and colleagues (1959) were among the first to demonstrate the numerous ways of anastomosing a patch of ileum to the native bladder. Virtually all surgeons recognize that ileum should be detubularized and reconfigured to achieve the most spherical shape possible (Q.15). 
A segment of ileum at least 15 to $20 \mathrm{~cm}$ proximal to the ileocecal valve should be selected. The distal portion of terminal ileum is unique from a physiologic standpoint and should be avoided. The isolated segment should be 15 to $40 \mathrm{~cm}$ in length, depending on patient's size, native bladder capacity, type of reconfiguration and desired final capacity. With short ureters, an extra tail of isoperistaltic ileum can be useful to reach the foreshortened ureters. This requires creation of an ileonipple valve to prevent reflux, as in the Kock or hemi-Kock pouch. This type of construction may require up to $60 \mathrm{~cm}$ of small intestine.

The segment to be used should have an adequate mesentery to reach the native bladder without tension. After selecting the appropriate segment, the mesentery is cleared from the bowel at either end for a short distance to create a window. The bowel is divided at these ends, and a handsewn ileoileostomy or stapled anastomosis performed. The harvested ileal segment is irrigated clear with $0.25 \%$ neomycin solution and opened on its antimesenteric border. The ileum is most commonly folded in a U shape, although longer segments can be folded further into an $\mathrm{S}$ or $\mathrm{W}$ configuration. The ileum is then anastomosed to itself with running absorbable sutures. The suture line should approximate the full thickness of ileum to ileum while inverting the mucosa. If not opened previously, the bladder is incised in a sagittal plane. The anastomosis of the ileum to the native bivalved bladder is easily done when started posteriorly. The anastomosis may be done in a one-or two-layer fashion, always with absorbable suture. Permanent suture should never be used for any cystoplasty because it may serve as a nidus for stone formation. The mesenteric window at the bowel anastomosis is closed to prevent internal herniation.
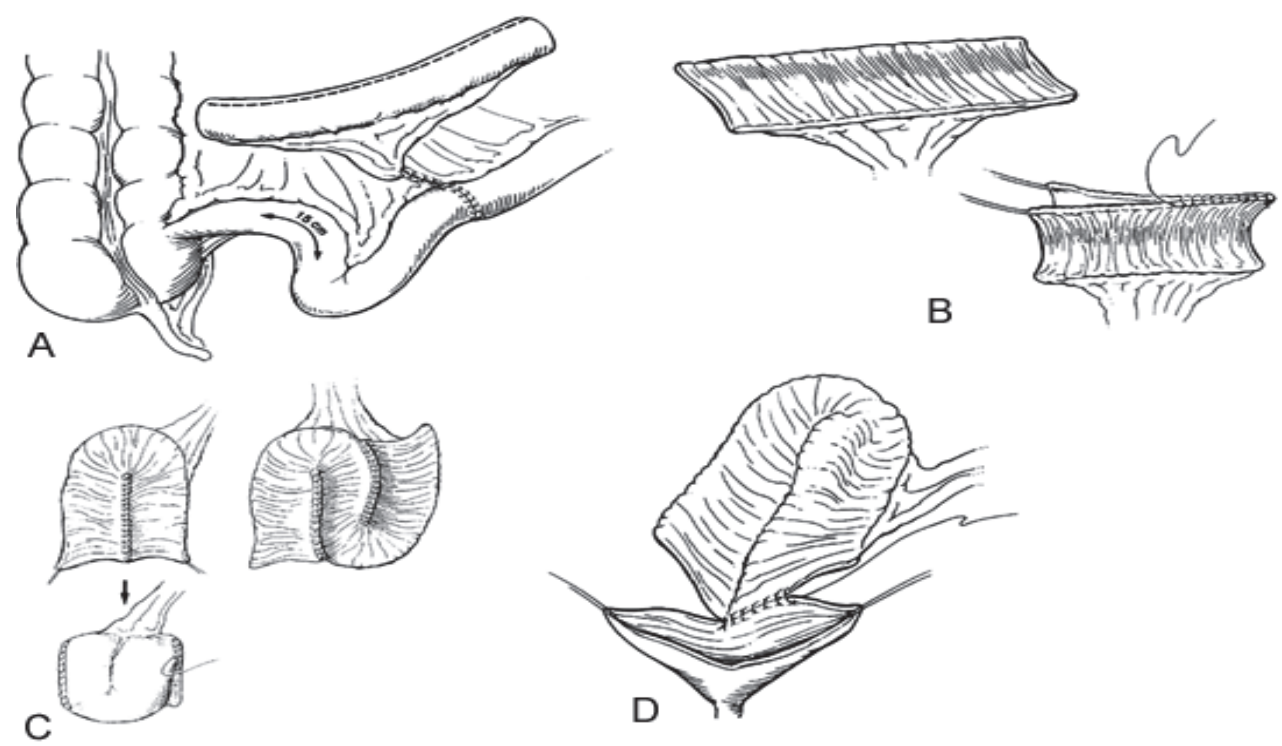

A: $15-40 \mathrm{~cm}$ segment of ileum proximal to the ileocecal valve is isolated and an ileoileostomy is performed. B: The isolated segment of ileum is opened along the antimesenteric border. The opened segment is then folded and the edges are sutured together. C: The opened segment is reconfigured to increase the surface volume. D: The reconfigured ileum is anastomosed to the opened bladder beginning at the posterior apex (1). 
Ileum does not allow for standard reimplantation of the ureters or the creation of a continent catheterizable channel (i.e., Mitrofanoff), but newer techniques such as the seromuscular trough, as described by Abol-Enein and Ghoneim (22) do allow the use of ileum, should these procedures be required. However, because of its muscle backing, native bladder (or a gastric flap) is still the primary choice for ureteral reimplantation or the construction of a Mitrofanoff valve.

Although the jejunum can be used for urinary reconstruction, yet the high incidence of metabolic complications (hyponatremic, hypochloremic and hyperkalemic acidosis) associated with use of this segment make it less desirable and thus rarely used.

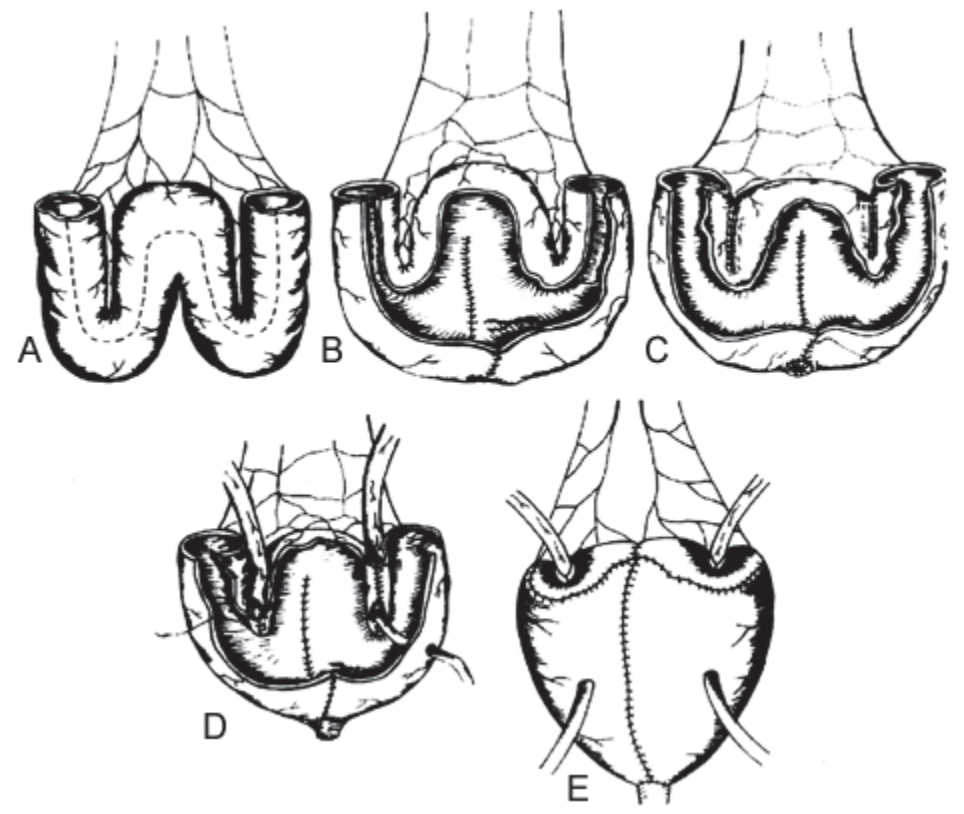

The seromuscular trough formed by anastomosing the edges of the ileum together allows for nonrefluxing ureteral reimplantation into the ileum (22).

\subsubsection{Advantages}

Ileum is the most commonly used bowel segment for bladder augmentation, as it is:'1) available in large quantity, 2) ease in handling and reconfiguration, 3) has a predictable and abundant blood supply, 4) most compliant segment of bowel, 5) produces moderate mucus compared to colon, 6) causes less severe metabolic complications than colon or stomach, 7) has fewer GI complications than cecum,

\subsubsection{Disadvantages}

The disadvantages in using ileum include: 1) occasional short mesentery that cannot reach the pelvis, 2) possible development of diarrhea and vitamin $B_{12}$ deficiency, 3) difficulty with creation of submucosal tunnels, 4) hyperchloremic, hypokalemic melabolic acidosis, 5) bowel obstruction, 6) stone formation, 7) mucus production, 8) urinary tract infections, 9) tumor formation which is a risk with large bowel segments as well (14). 


\subsection{Sigmoid cystoplasty}

\subsubsection{Technical considerations}

Use of the sigmoid colon for augmentation cystoplasty was first reported by Lemoine in 1912 (Q.15) and until nowadays continues to be used commonly.

Because of the strong unit contractions of the sigmoid, it is imperative to detubularize and reconfigure the segment used to provide maximal compliance and disruption of contractions. Fifteen to $20 \mathrm{~cm}$ of sigmoid colon is identified and mobilized. Its mesentery is transilluminated to identify the vascular arcade, after which the surgeon must ensure that the segment can reach the bladder without tension. If so, the bowel segment is divided between clamps and a colocolostomy perfomed. Detubularization and reconfiguration is done in a fashion determined by the surgeon's preference. The sigmoid patch is anastomosed to the bivalved bladder.

Sigmoid colon segments are usually reconfigured in one of two ways. Mitchell (1986) suggested closing the two ends and then opening the segment longitudinally opposite its blood supply (23). The segment easily fits on the bivalved bladder. The bowel segment may fit better in either the sagittal or the coronal plane. More radical reconfiguration, and perhaps breakup of unit contractions, may be achieved by folding the sigmoid segment in a U-Shape.
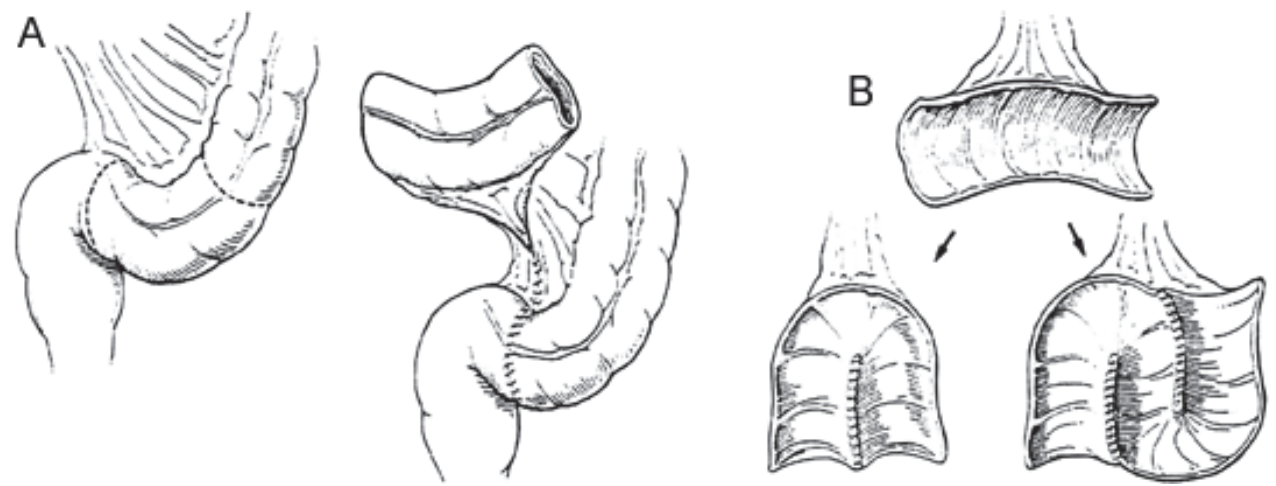

A: A segment of the sigmoid is resected and bowel continuity is reestablished. B: The isolated segment of sigmoid is opened on its antimesenteric border and then reconfigured before being anastomosed to the bladder (4).

\subsubsection{Advantages}

The major advantage of the use of sigmoid colon is the redundancy that is present especially in the spina bifida population. The mobile portion of the sigmoid is so redundant in these children that it often lays in the right lower quadrant. It can be easily opened and reconfigured into a U-shape to increase compliance. The thicker muscle can be used for an antirefluxing ureteral anastomosis as well as for placement of a tunneled continent catheterizable.

\subsubsection{Disadvantages}

The major disadvantage of the use of the sigmoid colon is the lessened ability to create a large capacity, compliant reservoir. The diameter of the sigmoid may be only similar to the ileum. In 
certain circumstance, at least a 20 to $30 \mathrm{~cm}$ segment of colon is required to create a large enough reservoir. This amount of sigmoid colon can occasionally be difficult to obtain in the non-spina bifida population. In the Indiana series, the highest spontaneous perforation rate occurred among those with sigmoid cystoplasties (19). However, this has not been observed in other large series. Finally hyperchloremic acidosis is more common when the sigmoid colon is employed, compared to other bowel segments. Frequently, these patients will need lifelong alkalinizing agents but this can also be true after ceco or ileocystoplasty as well (24).

\subsection{Cecocystoplasty and ileocecocystoplasty \\ 3.3.1 Technical considerations}

Couvelair described the use of the cecum for augmentation cystoplasty in 1950 (Q.15). Numerous reports of simple cecocystoplasty have appeared since then. Presently, cecocystoplasty is an uncommon operative procedure; it has largely been replaced by various forms of ileocecocystoplasty.

With the ileocecocystoplasty technique, the cecum is opened, reconfigured, and used to augment the bladder alone, leaving a segment of ileum to reach the ureters or to create a continent abdominal wall stoma based on imbrication of the ileocecal valve and proximal ileum. Conversely, the ileal segment can be opened and used as a patch on the cecal segment before augmentation cystoplasty. Many modifications of the technique exist, but all start with mobilization of the cecum and right colon by incising the peritoneum along the white line of Toldt up to the hepatic flexure. Approximately 15 to $30 \mathrm{~cm}$ of the terminal ileum is used. The length of the ileal segment depends on the technique employed. As with all intestinal cystoplasties, before division of the bowel segment, it should be certain that it will reach the bladder without tension.

The isolated ileocecal segment is irrigated clear with neomycin solution and opened on its antimesenteric border through the ileocecal valve for its entire length. In the typical ileocecal augmentation, the ileal and cecal segments are of equivalent length such that the borders of the open segment can be anastomosed and then folded on themselves to form a cup cystoplasty. The anastomosis of the reconfigured segments is done in a one-or two-layer closure with absorbable suture. The opening should be left large enough to provide a wide anastomosis to the bivalved bladder. If more volume is necessary, the ileal segment can be significantly lenghtened, allowing it to be folded before anastomosis to the cecum. The Mainz ileocystoplasty uses an ileal segment twice the length of the cecal segment. The opened edge of the cecal portion is anastomosed to the first portion of the ileal segment. The first and second portions of the ileal segment are next approximated. The compound ileocecal patch is then anastomosed to the bladder.

The ileocecal segment has been used extensively for reconstruction and bladder replacement in the adult population. It has been used less frequently in children because most of the patients undergoing augmentation cystoplasty are doing so because of neurovesical dysfunction. Those patients usually have neuropraxic bowel dysfunction as well. Removal of the ileocecal valve in such children can result in intractable diarrhea (24, 25). Use of the ileocecal valve in such patients should be avoided unless other advantages of the segment outweigh the risk of diarrhea and fecal incontinence.

\subsubsection{Advantages}

One potential advantage of ileocecocystoplasy is the presence of the appendix. Particularly in children, the appendix is useful in the creation of a reliable continent abdominal wall 

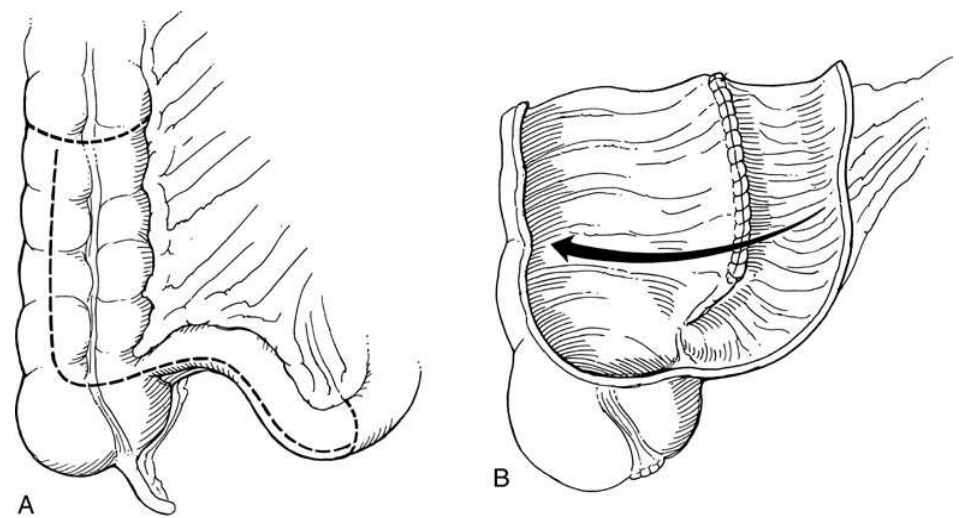

Ileocecocystoplasty. A). An ileocecal segment is selected. The length of segment chosen depends on the technique employed. After removal, it is opened on the antimesenteric border (dashed lines). B). The opened ileal and cecal segments are anastomosed to form a cup in the standard ileocecocystoplasty (15).

stoma. The appendix may be removed with a small cuff of cecal wall and tunneled into the native bladder or a tenia of the cecal segment to provide a continent mechanism. Likewise, it may be left in situ and the base safely tunneled by creating a window in the mesoappendix. If the appendix is not to be used, an appendectomy is performed with the standard ileocecocystoplasy.

There are further advantages to the use of the ileocecal segment. Antireflux tunnels can easily be made into the tenia of the cecum when necessary. Again, for the short ureter, a tail of ileum can be left intact to bridge the gap, with the imbricated ileocecal valve used for antireflux. The same imbrication technique can be used to create a continent abdominal wall stoma as with the appendix. Cain and Husmann (1994) and Cain et al (1999) have proposed using the ileocecal segment for augmentation with the plicated ileal segment brought to the abdominal wall as a catheterizable stoma, as in the Indiana pouch (26,27). Another major advantage of these segments is the use of a portion of bowel that has a large diameter resulting in a capacious and compliant reservoir that often fits the bladder base rather nicely. It also has a well-defined reliable blood supply.

\subsubsection{Disadvantages}

The major disadvantage to the use of the ileocecal segment is related to the loss of the ilieocecal valve. Patients with neurologic disorders or short gut often have an increased incidence of diarrhea and difficulty with fecal continence. In addition, this segment is not available in the cloacal exstrophy population who has little to no hindgut. The ileocecal segment also reabsorbs urinary wastes which may result in hyperchloremic acidosis. Finally, cecum usually produces more mucus than the ileum which can lead to increased infections and stone formation.

\subsubsection{Summary}

Through the early 1980s, the cecum and sigmoid colon were more commonly used than ileum for enterocystoplasy. However, because of the shorter mesenteries, increased mucus 
production, and difficulty with configuration that is associated with large bowel, ileum has come to be the preferred segment of bowel for enterocystopasty for most surgeons. However, detubulairzed large bowel is still used for simple bladder augmentation in select patients (14).

\subsection{Gastrocystoplasty}

\subsubsection{Technical considerations}

Two basic techniques exist for the use of stomach in bladder augmentation. Leong and Ong (1972) described the use of the entire gastric antrum with a small rim of body for bladder replacement. With their technique, the left gastroepiploic artery is always used as a vascular pedicle. If the right gastroepiploic artery is dominant and the left vessel ends high on the greater curvature, a strip of body along the greater curvature from the left gastroepiploic artery to the antrum is maintained and provides adequate blood supply. Continuity of the upper gastrointestinal tract is restored by a Billroth I gastroduodenostomy (28).

In the second type of gastrocystoplasly, a gastric wedge based on the midportion of the greater curvature is used (29). The gastric segment used in this technique is made up mainly of body and consequently has a higher concentration of acid-producing cells. The right or left gastroepiploic artery may be used as a vascular pedicle to this segment. The right artery is commonly dominant and therefore is more frequently used. The wedge-shaped segment of stomach includes both anterior and posterior wall. The segment used may be 10 to $20 \mathrm{~cm}$ along the greater curvature, depending on patient age and size as well as the needed volume. The incision into the stomach is stopped just short of the lesser curvature to avoid injury to branches of the vagus nerve that control the gastric outlet. Branches of the left gastric artery just cephalad to the apex of this incision are suture ligated in situ before incision to avoid significant bleeding. Parallel atraumatic bowel clamps are placed on either side of the gastric incisions to avoid excessive bleeding or spillage of gastric contents. Alternatively, the stomach may be incised using a gastrointestinal stapling device that places a double row of staples, on each side of the incision (30). The staple lines, however, must be excised. The native stomach is closed in two layers using permanent sutures on the outer seromuscular layer.

The short gastric branches of the gastroepiploic artery to the antrum on the right or to the high corpus on the left are divided to provide mobilization of the gastroepiploic pedicle leaving the short gastric branches to the augmentation segment intact. In order that the eventual pedicle would be long enough to reach the bladder, the appropriate segment may be higher on the greater curvature if the right vessel is used as a pedicle, or lower if based on the left.

The vascular pedicle, with omentum, should not be free-floating through the abdomen. The segment and pedicle may be passed through windows in the transverse mesocolon and mesentery of the distal ileum and carefully secured to the posterior peritoneum. Despite careful consideration for an adequate pedicle length, on occasion the gastric segment initially does not reach the bladder without tension. Either gastroepiploic artery may be mobilized closer to its origin for further length. The first few branches from the gastroepiploic artery to the isolated gastric segment may also be divided. Because of the rich submucosal arterial plexus in the stomach, devascularization of the isolated segment does not result. Rarely, it may be necessary to approximate some of the isolated gastric segment to itself in one corner. The gastric segment should be approximated to the native bladder 
with one or two layers of absorbable sutures, taking care to invert the mucosa. Usually the gastric wedge fits well with the bivalved bladder.

Raz and colleagues (1993) have described the use of a much longer, narrower segment of stomach based along the greater curvature. Use of this segment, which includes both body and antrum, somewhat narrows the lumen of the stomach in its entire length except at the fundus and pylorus (31) Raz and colleagues (1993) isolated this segment with the use of a gastrointestinal stapler so that the native stomach was never open. Histamine 2 receptor blockers are often given in the early postoperative period to promote healing (31).
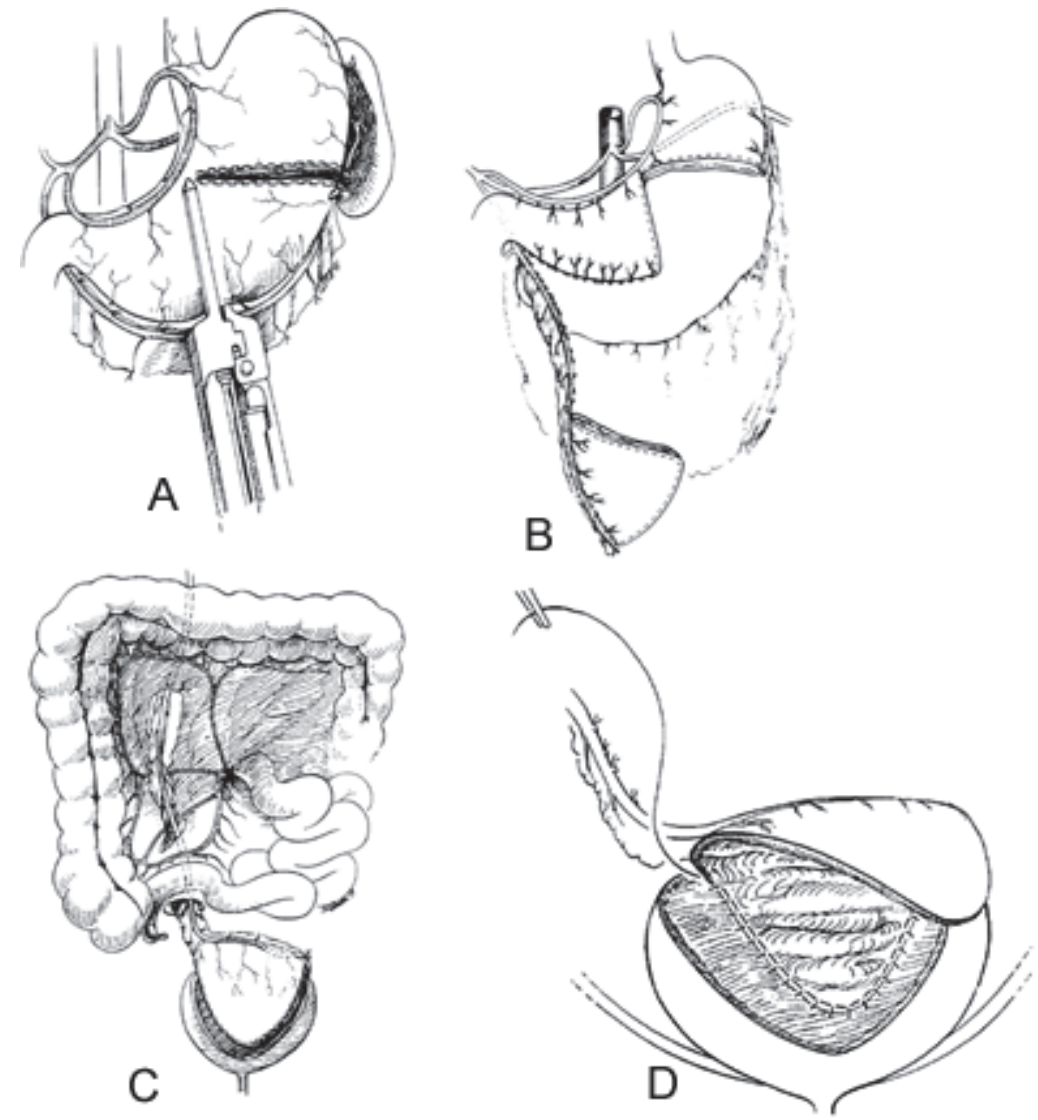

A). A wedge from the body of the stomach is harvested with a stapling device. B). The gastric wedge usually is based on the blood supply from the right gastroepiploic vessel. C). The gastric wedge is brought through the transverse colon and small bowel mesentery to reach the bladder. D). The gastric wedge is sutured to the bladder in two layers (1).

\subsubsection{Patient selection for gastrocystoplasty}

The stomach is unique with special physiologic and metabolic properties. Given the specific advantages and disadvantages that gastric segments exhibit in comparison to intestinal 
segments, gastrocystoplasty appears to be most appropriate for patients with renal insufficiency and for those with short intestines, as well as in patients with cloacal exstrophy. Also since the development of the hematuria dysuria syndrome is fairly common following gastrocystoplasty, this type of augmentation is most appropriate in patients who have minimal or no perineal and urethral sensation. If gastrocystoplasty is performed in patients that are sensate, it is important to ensure that patients are completely continent. Caution should be exercised when considering gastrocystoplasty in a patient with end stage renal disease in need of transplantation since ulcer formation and perforation of defunctionalized bladders have been reported (32). In general, patients that fulfill the preoperative criteria for conventional enterocystoplasty can also be considered candidates for gastrocystoplasty.

\subsubsection{Advantages}

Surgically, the stomach is relatively thick and easy to work with. It is readily accessible and has a rich reliable vascular supply. The suppleness of the stomach and the well-defined submucosal plane makes it ideal for reimplantation of ureters and continent catheterizable stomas. Use of stomach for bladder augmentation has clear advantages in patients with renal insufficiency due to its ability to secrete acid. This allows for buffering of systemic acidosis and lessens the need for bicarbonate supplementation. The resultant acid urine also appears to decrease the incidence of bacteriuria.

In comparison to other intestinal segments, there is also decreased mucus production and stone formation. The inherent musculature of the gastric segment may also offer an additional advantage over small and large bowel in more often allowing for spontaneous voiding that can result in more efficient emptying, less residual urine, and decreased need for intermittent catheterization. (33, 34). Lastly both gastrocystoplasty and ileocystoplasty can be accomplished laparoscopically which offers significant advantages in more rapid patient recovery following surgery ${ }^{(35)}$.

\subsubsection{Disadvantages}

The main disadvantage of gastrocystoplasty that currently limits its widespread use in children with a neuropathic bladder is the high incidence of hematuria dysuria syndrome. This is most troublesome in patients that have a sensate urethra and perineum. Caution should be exercised in selecting patients who are sensate and are at risk for incontinence (i.e. bladder exstrophy) when other enteric segments are available.

\subsubsection{Results}

The urodynamic results of gastrocystoplasty are somewhat variable. Most authors report that it is useful in increasing capacity and compliance similar to large and small bowel (36). In studies that have analyzed both pre- and postoperative urodynamics, gastrocystoplasty has been shown to increase bladder capacity by approximately 150 to 200 percent (37, 38). However it should be noted that there is a wide range of results reported with regard to increased bladder capacity following gastrocystoplasty. In a recent series comparing the urodynamic findings and clinical outcomes following augmentation with stomach versus intestine, it was shown that both stomach and intestine are efficacious in improving compliance but that the use of ileum and colon results in a higher volume reservoir. Intestinal segments appear to expand more readily following augmentation than the 
stomach (39). Some of the differences in the literature regarding improvements in capacity and compliance following gastrocystoplasty may be in part explained by variable amounts of stomach that are harvested in individual patients. However, less volume expansion seems inherent to gastric segments compared to ileum and colon.

\subsubsection{Summary}

Gastrocystoplasty is a useful procedure in the management of children with a neuropathic bladder. However, it has unique properties and potential complications from those seen with conventional enterocystoplasty. From the available experience, it appears that gastrocystoplasty is best suited for patients with renal insufficiency and metabolic acidosis, patients with a small amount of bowel available for augmentation, and patients with an insensate urethra and perineum. Despite some of the metabolic and physiologic advantages of gastrocystoplasty, potential disadvantages still make ileum the preferred intestinal segment for the majority of patients undergoing enterocystoplasty at this time (14).

\subsection{Overall results of gastro-intestinal augmentation cystoplasty}

The effect of cystoplasty on the patient should be considered in two main categories. First, the effect of removal of a relatively small portion of the gastrointestinal tract for use in urinary reconstruction must be considered. Any more than rare development of gastrointestinal problems would be prohibitive, even if the results were perfect from the standpoint of the urinary bladder. Second the effect of augmentation cystoplasty on the urinary bladder must be reviewed. The primary goal of augmentation is to provide a compliant urinary reservoir. Therefore the main consideration after augmentation is the storage pressure and capacity that are achieved. Any other effect in the urinary bladder is a side effect or complication that exists because bowel is not a perfect physiologic substitute for native bladder.

\subsubsection{Bladder compliance after augmentation}

An early lesson of past clinical experience with augmentation cystoplasty is the value of detubularization and reconfiguration of the bowel segment $(16,17)$. Bowel in its native, tubular form continues to display peristalsis or mass contraction. The tubular form does not maximize the volume achieved for the surface area of bowel used. Hinman (1988) demonstrated with a mathematical model that the maximum volume achieved for a given surface area occurs when a sphere is created. No finished cystoplasty is a perfect sphere but, it should approach that shape as nearly as possible(16).

Many patients who historically underwent augmentation cystoplasty with a tubular segment of bowel have done well, but there have also been numerous failures caused by continued pressure in the bladder from the segment left in its native form. Some surgeons with extensive experience in augmentation cystoplasty and continent diversion have concluded that ileum is superior to other segments in terms of compliance after augmentation $(40,41,42)$.Rare reports have suggested superior results with colon compared to ileum. These reports have involved longer colonic segments that were reconfigured in a U shape. Good results have been achieved with all segments in most cases, and it is more important to use a bowel segment well than to choose a particular bowel segment for every patient. 
Lytton and Green (1989) demonstrated mass contractions generating pressures of 60 to 110 $\mathrm{cm} \mathrm{H}_{2} \mathrm{O}$ in right colon reservoirs despite detubularization (44). Such pressures approach those observed in native cecum (45). Hedlund and coworkers (1984) reported pressures of only $25 \mathrm{~cm} \mathrm{H}_{2} \mathrm{O}$ in detubularized cecal segments 1 year after reconstruction (46). Placement of an ileal patch on a cecal segment can be a more effective mean of decreasing mass contractions than simple reconfiguration $(47)$.

Sidi and associates (1986) demonstrated early peak bladder pressures of $41 \mathrm{~cm} \mathrm{H} 2 \mathrm{O}$ after cup-patch sigmoid cystoplasty that improved with time (48). Goldwasser's review of enterocystoplasty using detubularized ileum and colon demonstrated contractions greater than $15 \mathrm{~cm} \mathrm{H}_{2} \mathrm{O}$ in $42 \%$ of patients after ileocystoplasty, compared with, $60 \%$ after colocystoplasty(18). Significant contractions, defined as those greater than $40 \mathrm{~cm} \mathrm{H}_{2} \mathrm{O}$ at a volume of less than $200 \mathrm{ml}$, were not noted in any of the ileal augmentations but did persist in $10 \%$ of cecal cystoplasties. In continent urinary diversion, ileal reservoirs have been noted to have lower basal pressures and less motor activity (24). Cecal reservoirs have been noted to generate more pressure per given volume than ileum despite detubularization and to exhibit more obvious uninhibited contractions (49).

Any problems with pressure after augmentation cystoplasty usually occur because of uninhibited contractions, apparently in the bowel segment. It is extremely rare not to achieve an adequate capacity or flat tonus limb unless a technical error has occurred with use of the bowel segment. Occasionally, a small, scarred pelvis prevents adequate expansion of the augmented bladder. When pressure contractions occur in the bladder after augmentation, they are often noted on a rhythmic or sinusoidal pattern, occasionally with increasing amplitude (15).

For most patients, the pressure contractions noted urodynamically are of theoretical interest only and have not affected the clinical result. Contractions that begin at low amplitude later in filling and progress only near capacity may be of no clinical significance at all. Early contractions of higher pressure may occasionally result in persistent incontinence, delayed perforation, hydronephrosis, or vesicoureteral reflux. If patients have such clinical problems after augmentation, repeat urodynamic testing is necessary.

One cannot assume that the bladder is compliant after augmentation. Rhythmic contractions have been noted postoperatively with all bowel segments, although ileum seems the least likely to demonstrate remarkable urodynamic abnormalities, and stomach the most. Rhythmic contractions after cystoplasty have been noted in up to $62 \%$ of patients $(39,50)$. The segment of stomach initially described for augmentation using the body was much smaller in size than segments of ileum or colon commonly used for cystoplasty. The use of a slightly larger gastric segment that is longer along the greater curvature results in improved urodynamics after augmentation, with less prominent contractions $(38,50)$. The antral segment of stomach is less likely to demonstrate such contractions (33).

In perhaps the largest experience with pediatric bladder augmentation, Rink and associates (1995) at Indiana University found that approximately 5\% of several hundred patients had significant uninhibited contractions after augmentation cystoplasty causing clinical problems. Rink (1995) found that $6 \%$ of more than 300 patients required secondary augmentation of a previously augmented bladder for similar problems in long-term followup (51). These secondary augmentations represent true failures of the primary cystoplasty, not from any side effect or complication but from failure to achieve the objective capacity and compliance. In that series, sigmoid colon, followed by stomach and then ileum, was most likely to require reaugmentation. It should be noted that a colonic segment closed at 
the ends and not generally reconfigured otherwise was typically used in that experience. Other studies have suggested that stomach is more likely than colon to require secondary intervention (39).

\section{Bowel Segment}

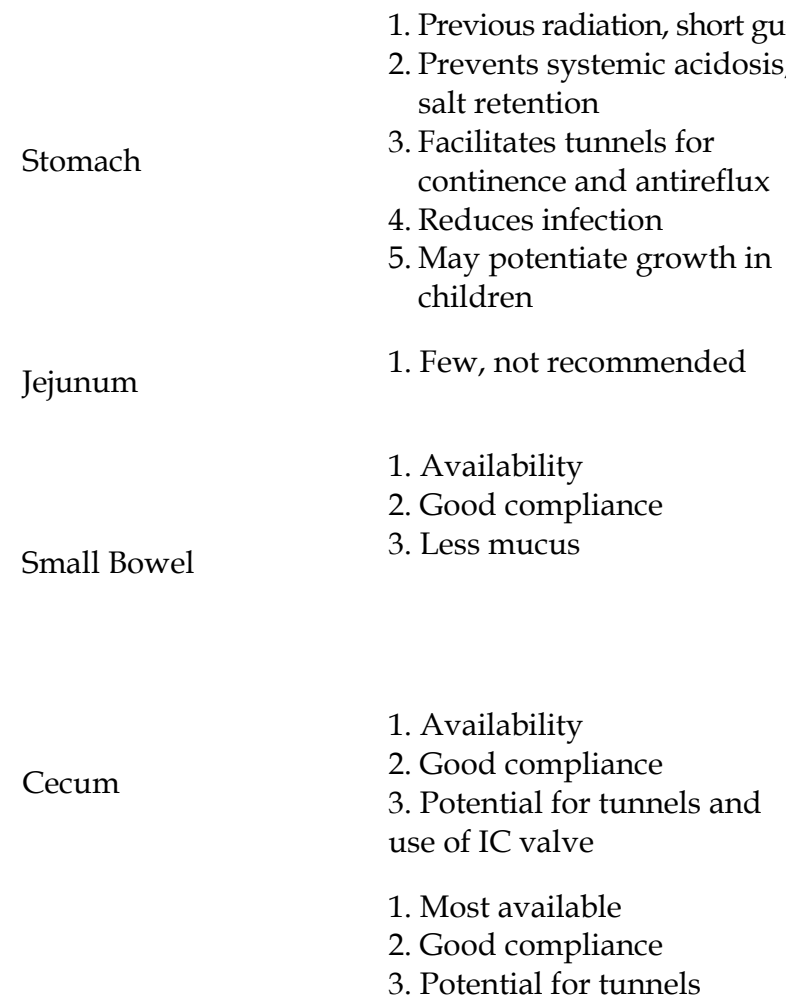

Sigmoid

\section{Advantages}

1. Previous radiation, short gut

Prevents systemic acidosis,

continence and antireflux

4. Reduces infection

May potentiate growth in children

1. Few, not recommended

1. Availability

3. Potential for tunnels and

2. Good compliance

\section{Disadvantages}

1. Acid secretion salt loss, metabolic alkylosis

2. Hematuria-dysuria syndrome

3. More difficult to use

1. Salt and water loss, metabolic acidosis

1. Metabolic acidosis salt resorption

2. Loss of resorption surface in GI tract (B12, folate) 3. Sometimes difficult to work with (no tunnels)

1. Metabolic acidosis, salt and water resorption 2. Loss of IC valve may cause diarrhea

1. Not available in some patients (radiation, constipation)

2. Metabolic acidosis, salt and water resorption

3. Possible increased potential for rupture

GI, gastrointestinal.

Advantages and disadvantages of specific bowel segments (1)

\section{Complications of gastrointestinal cystoplasty}

\subsection{Complications of bowel segment Isolation 4.1.1 Postoperative bowel obstruction}

Postoperative bowel obstruction is uncommon after augmentation cystoplasty, occurring in approximately $3 \%$ of patients. The rate of obstruction is equivalent to that noted after conduit diversion or continent urinary diversion $(51,52)$. Delicate handling of tissues, closure 
of mesenteric windows, and elimination of sites of internal herniation help to avoid obstruction. The incidence of bowel obstruction is low regardless of the gastrointestinal segment used and should not influence the choice of a particular segment for enterocystoplasty (15).

\subsubsection{Malabsorption abnormalities and diarrhea}

Loss of the distal ileum may result in fat malabsorption and decrease bile salt and fat soluble vitamin absorption. The distal ileum and ileocecal valve are important for reabsorption and regulation of bowel function. When fecal losses of bile acids exceed production from the liver, fat malabsorption occurs. Steatorrhea then occurs with possible impaired absorption of lipids and fat soluble vitamins (A, D, E \& K).

The diarrhea associated with bile acid irritation of the colon can be severe. The secretary diarrhea is secondary to unabsorbed bile salts, causing active secretion of chloride and water in the colon. Reports of chronic diarrhea after bladder augmentation alone have been rare. Diarrhea can occur after removal of large segments of ileum from the gastrointestinal tract even with the preservation of the ileocecal valve (more than $100 \mathrm{~cm}$ ). Although the length of the segments typically used for augmentation rarely are problematic unless other problems coexist $(53,54)$. The use of a typical colonic segment for augmentation only rarely results in a change in bowel function and is less of a risk than the use of ileum.

Removal of a segment from the gastrointestinal tract that includes the ileocecal valve is the most likely procedure to cause diarrhea. Patients with neurogenic dysfunction have significant diarrhea after such displacement. Roth et al (1995) reported that $23 \%$ of patients in their experience had chronic diarrhea after ileocecal urinary diversion and $11 \%$ when ileum alone was used (53). Some children with neurogenic impairment depend on controlled constipation for fecal continence. Removal of the ileocecal valve from the gastrointestinal tract may significantly decrease bowel transit time. Loss of the valve can also allow bacterial backflow into the ileum, and the organisms may interfere with metabolism of fat and vitamin B12.

Oral cholestyramine and a low fat diet can be used to treat the diarrhea. Diarrhea as a result of ileocecal valve resection with decreased transit time can be managed with codeine or lomotil. Some authors reported higher incidence of hypertriglyceridemia and gall stones (54).

\subsubsection{Vitamin B12 deficiency}

When portions of the alimentary tract are used for urinary reconstruction, nutritional deficiencies can occur. Resection of the terminal ileum can result in vitamin B12 deficiency. Vitamin B 12 (cyanocobalamin) cannot be synthesized by human tissues, so humans must receive their vitamin B12 supply from dietary sources. In the stomach, vitamin B 12 is released from food by hydrochloric acid and digestive enzymes. Intrinsic factor binds to vitamin B12 in the duodenum, and then attaches to receptors in the distal ileum. Vitamin B12 is then stored in the liver and supplies last up to three years.

Deficiency of vitamin B12 causes a megaloblastic anemia and neurologic changes including peripheral neuropathies, optic atrophy, degenerative changes of the spinal cord, and dementia in the late stages (54). Several reports in the literature describe patients in whom the terminal ileum is resected for urinary diversion with a 3.3 to 20 percent incidence of vitamin B12 deficiency (55). Fifty centimeters of ileum appear to be the critical length, with larger resections of small bowel placing the patient at risk for vitamin deficiency (56). Neurological 
symptoms may occur before serum levels are depressed and without megaloblastic anemia. Pannek and associates recommend starting therapy with $100 \mathrm{mcg}$ of hydroxycobalamin injected intramuscularly monthly one year after surgery for patients losing more than $50 \mathrm{~cm}$ of terminal ileum (56).

\subsection{Metabolic complications of gastrointestinal augmentation cystoplasty}

To understand the potential complications of gastrointestinal cystoplasty, one must take into account many factors. These factors include the length and the type of intestinal segment, the general health of the patient, the time urine is in contact with bowel mucosa, and the basic underlying renal and hepatic function.

Serum electrolyte abnormalities are dependent upon the segment of bowel used. Other factors include the constituents of urine in the augmented bladder which depend on many factors including fluid intake, diet and intercurrent illness, gastroenteritis, and dehydration (57).

\subsubsection{Hyperchloremic metabolic acidosis}

Ileum and colon have similar solute transport properties. Normal urine has higher potassium and hydrogen ion concentration and a lower sodium concentration than normal intestinal contents.

Hydrogen ions in the urine must be excreted with a buffer. As a patient becomes acidotic, the kidneys initially excrete acid buffered with phosphates or sulfates, or titratable acids. As the acidosis becomes chronic however, the kidney generates ammonia (NH3) from the conversion of glutamine to alpha-ketoglutarate. Ammonia buffers the free hydrogen ion and becomes ammonium, $\mathrm{NH}_{4}{ }^{+}$. Ileal and colonic mucosa will therefore secrete sodium and bicarbonate and absorb hydrogen, chloride, and ammonium upon exposure to urine, resulting in the development of a hyperchloremic metabolic acidosis (57). Patients with good underlying renal function can overcome this acid reabsorption by excreting even more urinary acid.

The majority of the acid load following augmentation cystoplasty is the result of the net ammonium absorption. Ammonia, ionized ammonium and chloride are absorbed when ileum or colon is exposed to urine, and the majority of the acid load is from the absorbed ammonium chloride. Ammonium and hydrogen are then transported with chloride to maintain electric neutrality (58).

In 1987, Mitchell and Piser noted that essentially every patient after augmentation with an intestinal segment had an increase in serum chloride and a decrease in serum bicarbonate level, although full acidosis was rare if renal function was normal (4). Mild metabolic acidosis is found in 15 percent of patients with ileal conduit diversions. As many as ten percent of patients with ileal conduits require therapy for persistent acidosis. Similarly, 10 to 15 percent of patients with colon conduits develop acidosis. Due to increased urine contact time, metabolic acidosis after bladder replacement with ileum is found in 50 percent of cases. Over 50 percent of colonic reservoirs also have some degree of hyperchloremic metabolic acidosis. Initial reports of ureterosigmoidostomy patients indicate that they have as much as an 80 percent incidence of metabolic acidosis. The risk of acidosis also appears to correlate directly with length of bowel used $(54,59)$.

The absorptive properties of the intestinal segment may diminish over time. Histological changes occur, including mucosal atrophy and decreased villous height. These histologic 
findings are believed to cause a reduced absorptive capacity of bowel, however, other studies demonstrate no change in absorptive capacity of the intestinal segment despite histological changes (60). Most likely, the majority of individuals with metabolic derangement do not develop significant changes in electrolyte transport to protect them from untoward complications.

Patients may present with signs and symptoms of fatigue, diarrhea, weight loss, anorexia, and polydipsia. Laboratory studies demonstrate a significant non-anion gap acidosis with hyperchloremia and azotemia. Arterial blood gases values are more sensitive than serum bicarbonate or chloride levels for detection and early management of acidosis (61).

Acute management includes prompt drainage with treatment of any underlying urinary tract infection and correction of any electrolyte abnormalities. Treatment of mild and chronic forms of metabolic acidosis involves the use of alkalizing agents. Sodium bicarbonate and sodium citrate are useful in restoring acid-base balance. They, however, have untoward side effects, with sodium bicarbonate producing considerable gas and sodium citrate being very distasteful. To neutralize the acid load, supplementation of $1-2$ $\mathrm{mEq} \mathrm{kg} /$ day of alkali is usually sufficient. In patients with refractory hyperchloremic metabolic acidosis, and those who cannot tolerate or have a contraindication to the alkalizing agents, chlorpromazine has been used successfully in an adult patient with refractory metabolic acidosis. Chlorpromazine and nicotinic acid inhibit cyclic adenosine monophosphate and thereby inhibit chloride transport and absorption in canine models (62). The usefulness of these agents in humans has not been clinically validated.

\subsubsection{Hypokalemia}

Hypokalemia can occur in patients with augmentation cysloplasty. The depletion of potassium stores is likely due to the renal wasting of potassium and the chronic metabolic acidosis which causes intracellular potassium depletion. Compared to colon, ileal segments have been shown to have a greater ability to reabsorb potassium when exposed to high concentrations of the ion in urine. Chronic diarrhea may be also a contributing factor for hypokalemia.

The treatment is exogenous potassium replacement. Once the acidosis is corrected, there will be an influx of potassium into the cell because of the extracellular potassium shift. This can lead to profound hypokalemia if not recognized and treated promptly.

\subsubsection{Hypocalcemia / Hypomagnesemia}

Hypocalcemia and hypomagnesemia are uncommon complication of augmentation cysloplasty. Chronic metabolic acidosis causes loss of calcium from several mechanisms. Symptoms include tetany, tremors and irritability. Treatment consists of calcium replacement either enterally or parenterally depending on the severity. Hypomagnesemia, however uncommon, is due to malabsorption, renal loss, and decreased renal tubular absorption with acidosis. Symptoms are similar to hypocalcemia and the treatment again is exogenous replacement (57).

\subsubsection{Ammioniagenic encephalopathy}

Urinary ammonium excreted by the kidneys is reabsorbed by the intestinal segment, and then returned to the liver via the portal circulation. The liver metabolizes ammonium to urea via the ornithine cycle. The liver usually adapts to the excess ammonia in the portal circulation without difficulty and rapidly metabolizes it. In the setting of hepatic 
dysfunction, the hepatic reserve for ammonium metabolism may be exceeded, resulting in the rare complication of ammoniogenic coma. The syndrome also has been described in patients with normal hepatic function (63).

Systemic bacteremia, with endotoxin production, inhibits hepatic function and may precipitate this clinical entity. Urinary tract infections with urea-splitting organisms may also overload the ability of the liver to clear the ammonia. If this syndrome occurs in a patient suspected of having normal hepatic function, systemic bacteremia or obstruction of urinary drainage should be suspected.

Good urinary drainage and treatment of the offending urinary pathogens usually prevents development of the syndrome. Treatment consists of prompt drainage with a Foley catheter. Systemic antibiotics treat the possible underlying infection, and neomycin or lactulose is given to reduce absorption of ammonia in the gastrointestinal tract (54).

\subsubsection{Bone disease and retarded growth}

A potential long-term complication of intestinal diversion is bone demineralization. This clinical entity was initially found in children developing rickets after ureterosigmoidostomy, but has also been noted in adults with osteomalacia following ureterosigmoi-dostomy, ileal replacement of ureters, and coloplasty ${ }^{(64)}$. In rickets and osteomalacia, bone mineral loss is replaced with osteoid resulting in decreased bone strength. Fortunately, severe defects in bony demineralization are not common.

The cause of bone demineralization appears complex and multi-factorial, with changes in acid-base balance being the major contributing factor. In chronic acidosis, bone serves to buffer the excess acids. Bone minerals released into the circulation, including carbonate and phosphate, buffer the hydrogen ions, decreasing the axial skeleton calcium content. Systemic acidosis also appears to inhibit the conversionof of 25 hydroxycholecalciferol to 1,25 dihydroxycholecalciferol and appears to activate osteoclasts producing further bone resorption. Additionally, patients with urinary diversions have increased excretion of calcium and sulfate. Sulfate has been shown to cause increased excretion of calcium by the kidneys. The effect of sulfate is potentiated by acidosis. Chronic metabolic acidosis therefore results in negative calcium and phosphate balances (65).

Changes in acid-base status may be subtle with patients displaying only a minimal decrease or normal serum calcium and magnesium level and mild depression of serum bicarbonate level. Most patients who present are asymptomatic; however, they may have occult bone mineral defects that place the patient at higher risk for increased orthopedic morbidity.

The diagnosis can be particularly difficult to detect. Parathormone and vitamin D levels are typically normal, and radiologic examination is usually unremarkable. Post-menopausal women and children are at high risk for bone demineralization with several studies showing a reduction in growth potential for children following enterocystoplasty.

Patients presenting with rickets or osteomalacia should have correction of their acid-base disturbance first. Vitamin D and calcium supplements are then used if remineralization does not occur. Administration of vitamin $\mathrm{C}$ or oral alkalizing agents to children with urinary diversion may help reinforce normal bone development and prevent bone destruction (66).

\subsubsection{Drug absorption toxicities}

Absorption of drugs excreted in urine from bowel segments can cause toxicities. One must be aware of the potential toxicities that can result from absorption of active drug such as methotrexate or metabolites in patients with augmentation cystoplasty (54). 


\subsubsection{Hypochloremic alkalosis}

Significant metabolic derangement can occur with gastric diversions. In contrast to ileum or colonic cystoplasty the stomach excretes chloride. This can lead to profound hypochloremic, hypokalemic alkalosis. It has been proposed that the alkalosis results from ongoing chloride loss from the gastric segment in the bladder in the face of decreased oral intake. The decreased ability to excrete bicarbonate from an impaired kidney may compound the problem. Gosalbez and associates (1993) demonstrated persistently increased traditional excretion of chloride despite profound hypochloremia, suggesting that inappropriate gastric secretion is probably the primary problem (39).

Patients may present with lethargy, mental status changes, intractable seizures, and respiratory compromise related to a compensatory respiratory acidosis (39). Patients are prone to suffer from severe dehydration secondary to a loss of fluid, chloride, and potassium from the gastric segment. A simple viral gastroenteritis illness may trigger severe symptoms of dehydration and alkalosis.

Replacement with normal saline and correction of serum potassium abnormalities usually corrects the metabolic abnormalities. Patients should maintain good oral and normal salt intake. Additional oral salt and potassium supplementation may be needed. Histamine-2 blockers and anticholinergic therapy may also be needed in patients with low-grade alkalosis. Refractory episodes of hypokalemic, hypochloremic metabolic alkalosis may be treated with inhibiting $\mathrm{K}+/ \mathrm{H}+$ exchange with such agents as omeprazole.

\subsubsection{Hematuria-dysuria syndrome}

Acid secretion by gastric mucosa may result in another unique problem after gastrocystoplasty, the hematuria-dysuria syndrome. Virtually all patients with normal sensation after gastrocystoplasty have occasional hematuria or dysuria with voiding or catheterization beyond that which is expected with other intestinal segments. All patients should be warned of this potential problem, although in most the symptoms are intermittent and mild and do not require treatment. Avoidance of gastrocystoplasty in patients with bladder exstrophy is recommended. The dysuria is certainly not a problem in patients with neurogenic dysfunction.

In the experience of Nguyen and coworkers (1993), 36\% of patients developed signs or symptoms of the hematuria-dysuria syndrome after gastrocystoplasty; $14 \%$ required treatment with medications, $9 \%$ on a regular basis. They believed that patients who are incontinent or have decreased renal function are at increased risk (67). The symptoms of the hematuria-dysuria syndrome respond well to administration of $\mathrm{H}_{2}$ blockers and hydrogen ion pump blockers. Bladder irrigation with baking soda may also be effective. It has been demonstrated that urinary $\mathrm{pH}$ may decrease remarkably after meals in those who have undergone gastrocystoplasty.

The signs and symptoms of the hematuria-dysuria syndrome are most likely secondary to acid irritation. Acid in urine may cause external irritation and skin excoriation. Recent work has suggested that Helicobacter pylori may play a role in this complication, as it may increase acid complications in the native stomach (68). Such problems are less frequent after antral cystoplasty, where there is a smaller load of parietal cells.

\subsubsection{Mucus production}

Intestinal segments continue to produce mucus after placement in the urinary tract. The proteinaceous material can potentially impede bladder drainage during voiding or CIC, 
particularly in pediatric patients who must use small-caliber catheters. Mucus may serve as a nidus for infection or stone formation when it remains in the bladder for long periods. Mucus production often increases after cystoplasty in the presence of cystitis. Colonic segments produce more mucus than ileum and gastric segments produce the least amount. Most patients do not require any routine bladder irrigations for mucus after gastrocystoplasty. Villous atrophy in the ileum has been documented after long-term placement in the urinary tract. It has been suggested that such atrophy may result in decreased mucus production

Hendren and Hendren (1990) noted a decrease in mucus production from colonic segments over years (3), however, others have not been impressed with such changes (51). Glandular atrophy in colonic mucosa has not been noted histologically. Routine use of daily bladder irrigations to prevent mucus build up may minimize complications of enterocystoplasty such as urinary tract infection and calculi.

\subsubsection{Urinary tract infection}

Bacteriuria is very common after intestinal cystoplasty, particularly among patients requiring CIC. Recent experience with bowel neobladders has demonstrated that patients who are able to spontaneously void to completion frequently maintain sterile urine. It appears that the use of $\mathrm{CIC}$ is a prominent factor in the development of bacteriuria after augmentation cystoplasty; regardless of the segment considered $(3,25)$.

Bacteriuria has been noted even when patients are maintained on daily oral antibiotics or antibiotic irrigation. Persistent or recurrent bacteriuria occurs in $50 \%$ of patients augmented with sigmoid colon, compared with $25 \%$ of those undergoing ileocystoplasty. Recurrent episodes of symptomatic cystitis requiring treatment occurred in $23 \%$ of patients after cecocystoplasty, $17 \%$ after sigmoid cystoplasty, 13\% after cecocystoplasty and $8 \%$ after gastrocystoplasty. Febrile attacks occurred in 13\% (51).

Not every episode of asymptomatic bacteriuria requires treatment in patients performing CIC. Bacteriuria should be treated for significant symptoms such as incontinence or suprapubic pain and perhaps for hematuria, foul-smelling urine, or remarkably increased mucus production. Bacteriuria should be treated if the urine culture demonstrates growth of a urea-splitting organism that may lead to stone formation.

\subsubsection{Calculus disease}

Patients with augmentation cystoplasty are at risk for upper and lower urinary tract calculus disease. These patients are chronically dehydrated from water loss through the diversion producing concentrated urine which may be a nidus for stone disease. Additionally urinary stasis, mucous production from the intestinal segment and frequent colonization with urea-spitting organisms places the patient at risk (3). Patients in whom large segments of ileum have been removed may develop enteric hyperoxaluria which places the patient at risk for calcium oxalate stone formation. Hypocitraturia a risk factor for stone disease may be found in patient with chronic metabolic acidosis and malabsorption abnormalities. Hypercalciuria is a result of the acidosis, and can lead to mobilization of calcium from bone and impaired reabsorption from acid renal tubule fluid.

Several series reported calculi in $18 \%$ of patients after augmentation cystoplasty $(3,43)$. Patients catheterizing through an abdominal wall stoma had the highest risk, probably because of incomplete emptying. Palmer and associates (1993) noted urolithiasis in 52\% of 
patients after augmentation cystoplasty. Rink and colleagues (1995) noted only an 8\% rate of bladder stone formation in 231 patients with long-term follow-up after enterocystoplasty (51). The reasons for these remarkable differences are not clear. Stones have been noted after the use of all intestinal segments, with no significant difference noted between small and large intestine. Struvite stones are less likely after gastrocystoplasty probably because of decreased mucus production and acid that minimizes bacteriuria. Uric acid calculi have rarely been noted in the bladder after gastrocystoplasty (37).

Patients should be instructed to keep adequately hydrated. Staples and nonabsorbable sutures should be avoided in the urinary diversion. Infection with urea-splitting organisms should be treated promptly. Patients should be instructed in the importance of regular reservoir catheterizing. Irrigation may be needed if one produces excessive amounts of mucous. Foods high in oxalate should be avoided in patients with enteric hyperoxaluria. Calcium citrate may be given to bind oxalate in the gut reducing its absorption. A low fat diet may reduce calcium saponification and increase the amount of calcium available to bind oxalate.

\subsection{Long-term complications 4.3.1 Tumor formation}

A well recognized complication of ureterosigmoidostomy has been the development of tumors, primarily adenocarcinoma, at the ureterocolonic anastomotic site. The latency for development of such tumors averaged 26 years and ranged from 3 to 53 years. Adenocarcinomas were the prominent tumors that developed, but benign polyps and other types of carcinoma were also found (15). The exact basis for the increased risk is unknown; however, N-nitroso compounds thought to originate from a mixture of urine and faces may be carcinogenic. These compounds have been noted in the urine of patients with conduit diversion and augmentation (69). Husmann and Spence (1990) suggested that those compounds are more likely enhancing agents rather than a lone cause for tumor development.

It has been proposed that inflammatory reaction at the anastomotic site may induce growth factor production, which, in turn, increases cellular proliferation (68). Filmer and Spencer (1990) identified 14 patients who developed adenocarcinoma in an augmented bladder, and several more have been reported since then. Nine of those tumors occurred after ileocystoplasty and five after colocystoplasty (70).

Experimental work in the rat demonstrated hyperplastic growth in the augmented bladder with all intestinal segments, with no segment showing any particularly increased risk (71). The applicability of such findings to humans is uncertain. The long latency period noted for tumor development after ureterosigmoidostomy suggests that short-term follow-up after augmentation cystoplasty is not adequate to evaluate tumor formation.

Patients undergoing augmentation cystoplasty should be made aware of a potentially increased risk for tumor development. Yearly surveillance of the augmented bladder with endoscopy should eventually be performed; the latency period until such procedures are necessary is not well defined. The earliest reported tumor after augmentation was found only 4 years after cystoplasty (72). Transitional cell carcinoma, hyperplasia, and dysplasia have also been noted near the anastomoses in humans. Urine cytology or flow cystometry may ultimately become useful in surveillance (73). 


\subsubsection{Delayed spontaneous bladder perforation}

Perhaps the most disturbing complication of augmentation cystoplasty is delayed bladder perforation. Patients presenting with spontaneous perforation after augmentation cystoplasty are usually quite ill with abdominal pain, distention and fever. Sepsis has been common. Nausea, decreased urine output, and shoulder pain from diaphragmatic irritation have also been noted. Perforations have been found in the evaluation of virtually asymptomatic pelvic masses Patients with neurogenic dysfunction often have impaired lower abdominal sensation and present later in the course of the illness; severe sepsis and death have occurred. Patients with perforation after gastrocystoplasty often present promptly because of acid irritation.

A high index of suspicion for perforation is necessary. Contrast cystography is diagnostic in most cases. Thorough technique is important to identify as many true-positive cases as possible with cystography. Some reports of perforations have noted a significant false-negative rate on cystography and suggested that ultrasonography and CT improve diagnostic accuracy. They recommended that one of those studies be done in any child with suspected perforation if the initial cystogram is negative $(74,75)$.

The cause of delayed perforations within a bowel segment is unknown. It has been suggested that perforation might be secondary to traumatic catheterization in some cases. It seems unlikely that catheterization trauma is the lone cause in most patients. The location of the perforations has been variable among patients and even in a single patient with multiple perforations. Perforations have occurred after augmentation in patients who did not catheterize at all. Others have suggested that trauma to the bowel caused by fixed adhesions that result in sheering forces with emptying and filling may result in perforation (15). Chronic, transmural infection of the bladder wall has also been proposed as a cause. Histologic examination of bowel segments adjacent to areas of perforation has revealed necrosis, vascular congestion, hemorrhage, and hemosiderin deposition compatible with chronic bowel wall ischemia. Chronic overdistention of the bladder might result in such ischemia. Chronic ischemia may thus play a significant role in at least some delayed bladder perforations.

Pope and associates (1998) reported perforations occurring in bladders with significant uninhibited contractions after augmentation. High outflow resistance may maintain bladder pressure rather than allowing urinary leakage and venting of the pressure, potentially increasing ischemia. Hyperreflexia alone is unlikely as a solitary cause of perforation, because the complication was essentially never recognized in the era before bowel detubularization and reconfiguration, when persistent pressure contractions were more common after augmentation cystoplasty. Once bowel is reconfigured, however, it may be more prone to ischemia if high pressure does persist.

Once spontaneous perforation has occurred, the chance of recurrence is significant. One third of patients with rupture in one series had a recurrence (74). Consideration must eventually be given to removal of the original segment and replacement by another after repeated perforation.

This problem has been noted with increasing frequency after augmentation cystoplasty and may involve all segments. There may be no particular increased risk of one intestinal segment over another. With the inconsistent differences across multiple large series, it is unlikely that any given enteric segment is at significantly increased risk for perforation and probable that multiple factors influence the risk for the complication $(15,20,48)$. 
The standard treatment for spontaneous perforation of the augmented bladder is surgical repair, as it is for intraperitoneal rupture of the bladder after trauma. There are reported series of conservative management for suspected perforation consisting of catheter drainage, antibiotics and serial abdominal examinations. It was successful in $87 \%$ of patients, although only 2 of 13 patients with suspected rupture had x-ray documentation unequivocally identifying a perforation (74). Even patients who do well with conservative management during the acute episode often require surgical intervention eventually. Such management may be a consideration in a stable patient with sterile urine. The surgeon should certainly have a low threshold for surgical exploration and repair.

\begin{tabular}{|c|c|c|c|}
\hline Problem & Stomach & Ileum & Colon \\
\hline $\begin{array}{l}\text { Segment } \\
\text { loss from } \\
\text { GI tract }\end{array}$ & $\begin{array}{l}\text { 1. Early satiety } \\
\text { 2. Decreased stomach- } \\
\text { acid production } \\
\text { 3. Increased gastrin } \\
\text { production }\end{array}$ & $\begin{array}{l}\text { 1. Decreased } \\
\text { absorption of B12, } \\
\text { folate, and iron } \\
\text { 2. Short-gut } \\
\text { syndrome }\end{array}$ & $\begin{array}{l}\text { 1. Diarrhea } \\
\text { 2. Water loss }\end{array}$ \\
\hline $\begin{array}{l}\text { Acid-base } \\
\text { balance }\end{array}$ & $\begin{array}{l}\text { 1. Alkalosis } \\
\text { 2. Hematuria/dysuria }\end{array}$ & $\begin{array}{l}\text { 1. Chronic } \\
\text { metabolic acidosis } \\
\text { 2. Ammonium and } \\
\text { chloride resorption }\end{array}$ & $\begin{array}{l}\text { 1. Acidosis } \\
\text { 2. Bicarbonate loss } \\
\text { 3. Ammonium } \\
\text { chloride resorption }\end{array}$ \\
\hline $\begin{array}{l}\text { Salt } \\
\text { balance }\end{array}$ & $\begin{array}{l}\text { 1. Sodium and } \\
\text { potassium loss }\end{array}$ & $\begin{array}{l}\text { 1. Sodium and } \\
\text { chloride resorption }\end{array}$ & $\begin{array}{l}\text { 1. Sodium and } \\
\text { chloride resorption }\end{array}$ \\
\hline Mucus & $\begin{array}{l}\text { 1. More soluble, less } \\
\text { apparent }\end{array}$ & $\begin{array}{l}\text { 1. Problem with } \\
\text { catheter } \\
\text { obstruction, } \\
\text { irrigation } \\
\text { necessary }\end{array}$ & $\begin{array}{l}\text { 1. Problem with } \\
\text { catheter obstruction, } \\
\text { irrigation necessary }\end{array}$ \\
\hline $\begin{array}{l}\text { Stone } \\
\text { formation }\end{array}$ & $\begin{array}{l}\text { 1. Rare problem (low } \\
\mathrm{pH})\end{array}$ & $\begin{array}{l}\text { 1. Can be a major } \\
\text { problem, } \\
\text { irrigations } \\
\text { recommended }\end{array}$ & $\begin{array}{l}\text { 1. Can be a major } \\
\text { problem, irrigations } \\
\text { recommended }\end{array}$ \\
\hline Infection & 1. Moderate & 1. Common & 1. Common \\
\hline Tumor & $\begin{array}{l}\text { 1. None documented } \\
\text { but too early to tell }\end{array}$ & 1. Reported & $\begin{array}{l}\text { 1. Significant in } \\
\text { ureterosigmoidostomy }\end{array}$ \\
\hline Perforation & $\begin{array}{l}\text { 1. Reported with } \\
\text { potential for ulcer } \\
\text { formation in anuric or } \\
\text { diverted patient }\end{array}$ & $\begin{array}{l}\text { 1. Reported, major } \\
\text { problem because } \\
\text { of potential for } \\
\text { infection }\end{array}$ & $\begin{array}{l}\text { 1. Reported, major } \\
\text { problem because of } \\
\text { potential for infection }\end{array}$ \\
\hline
\end{tabular}

Metabolic consequences of bladder reconstruction with bowel 


\section{Alternatives to gastrointestinal cystoplasty}

Currently, gastrointestinal segments are commonly used as tissues for bladder replacement or repair. However, gastrointestinal tissues are designed to absorb specific solutes, whereas bladder tissue is designed for the excretion of solutes. As mentioned, when gastrointestinal tissue is in contact with the urinary tract, multiple complications may ensue.

Because of the problems encountered with the use of gastrointestinal segments, numerous investigators have attempted alternative methods, materials, and tissues for bladder replacement or repair. These include autoaugmentation, ureterocystoplasty, methods for tissue expansion, seromuscular grafts, matrices for tissue regeneration and tissue engineering with cell transplantation. Some of these alternatives appear to hold promise, but none has stood the test of time for true comparison to intestinal cystoplasty.

An ideal tissue for increasing capacity and improving compliance would have transitional epithelium so as to be relatively impermeable and avoid metabolic changes. The lining would also prevent mucus production and, probably the increased potential for tumor development. The ability to augment the bladder without violation of the peritoneal cavity would also decrease morbidity. Two such alternative procedures are ureterocystoplasty and autoaugmentation. With ureterocystoplasty, there is good muscle backing of transitional epithelium, whereas collagen eventually backs the transitional mucosa of an autoaugmentation.

\subsection{Autoaugmentation}

\subsubsection{Techniques and results}

Cartwright and Snow (1989) described an ingenious method to improve bladder compliance and capacity using native urothelial tissue. In their procedure, known as autoaugmentation they excised detrusor muscle over the dome of the bladder leaving the mucosa intact to protrude as a wide-mouth diverticulum. Initially they made a midline incision through the bladder muscle with the bladder distended with saline so that mucosa bulged from the incision. The muscle was mobilized and excised laterally in each direction. The lateral edges of the detrusor muscle were then secured to the psoas muscle bilaterally to prevent collapse of the diverticulum. Their early experience with a small group of patients resulted in improved compliance in most, with increasing capacity in some ${ }^{(78)}$.

This producer has since been modified by a number of surgeons, particularly in adult patients, each providing a different name for the procedure depending on whether the detrusor muscle was simply incised (vesicomyotomy) or excised (vesicomyomectomy) to create the diverticulum. In an effort to determine whether incision or excision provided superior results, Johnson and colleagues (1994) performed 16 vesicomyotomies and 16 vesicomyomectomies in rabbits after previously reducing the bladder capacity. Functional bladder capacity in the animals increased by $43.5 \%$, and there was no statistical difference between the two techniques. They then performed vesicomyotomies (incision) in 12 patients with neurogenic bladder dysfunction and demonstrated a mean increase in capacity of $40 \%$ and a mean decrease in leak point pressure of $33 \%(78,80)$. They concluded that detrusor excision offered no advantage over incision. All patients demonstrated some increase in capacity ( $15 \%$ to $70 \%)$, and no patient in early follow-up clinically deteriorated and required enterocystoplasty.

Detrusorectomy, leaving a small cap of muscle at the dome through which a suprapubic tube can be placed, was proposed by Landa and Moorhead (1994). They have been 
concerned that, although these procedures usually improve compliance, the increase in volume is "modest" at best (81).

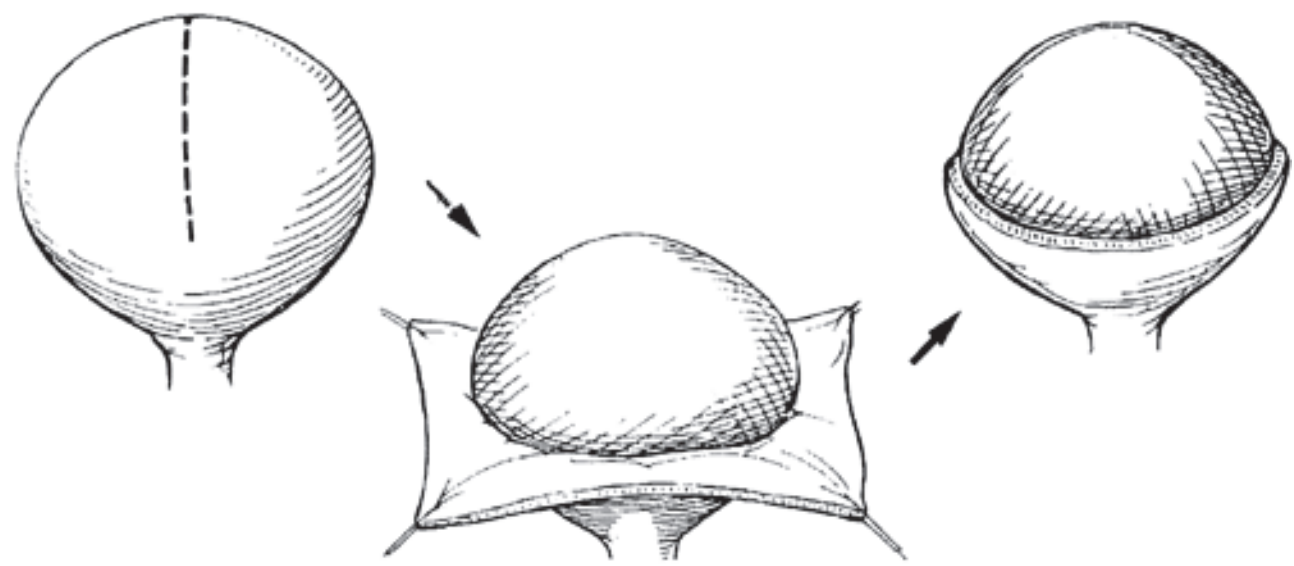

In autoaugmentation, the detrusor is excised leaving the urothelium to act as a diverticulum (1).

The efficacy of autoaugmentation in improving bladder capacity and compliance has been varied. Snow and Cartwright (1999) have follow-up of greater than one year in thirty patients. Nineteen of thirty patients had a neuropathic bladder secondary to spina bifida. All patients had preoperative urodynamic evidence of reduced bladder compliance and detrusor hyperreflexia. While clinical success has been dramatic in some, the overall results have been less impressive. One third of the patients had a significant increase in bladder capacity, an additional third were unchanged, while one third had actual loss of capacity. Evaluation of bladder compliance revealed that 60 percent had an improvement in compliance by greater than 50 percent in comparison to preoperative measurements, 20 percent had a 20 to 50 percent improvement, and the remaining did not change significantly. Overall fourteen patients $(47 \%)$ had excellent results, showing a significant improvement in compliance, capacity, and dryness. Seven patients $(23 \%)$ had fair results, described as stability or improvement of the upper tracts without scant improvement in the urodynamic parameters. Nine patients $(30 \%)$ had poor results, remaining wet or with worsening hydronephrosis (82).

Following autoaugmentation, the majority of patients remained on intermittent catheterization, although 20 percent demonstrated the ability to void spontaneously. Seven patients have required secondary enterocystoplasty following the initial autoaugmentation. Reoperative enterocystoplasty was not hampered by the prior detruseroctomy. The urothelial diverticulum at the time of augmentation cystoplasty was noted to be thick and fibrous similar to a leather bag ${ }^{(82)}$.

\subsubsection{Advantages}

The primary advantage that autoaugmentation has over conventional enterocystoplasty is that it preserves the patient's native urothelium in the augmented segment. This avoids the complications associated with enterocystoplasty related to the presence of heterotopic epithelium in contact with the urine including electrolyte disturbances, mucus, bladder 
calculi, hematuria dysuria syndrome, and later tumor occurrences. Technically, autoaugmentation is an extraperitoneal procedure that can be performed through a Pfannestiel incision and avoids the complications of bowel surgery including the development of intraperitoneal adhesions and postoperative bowel obstruction. Although autoaugmentation is performed without a formal cystotomy; other bladder procedures such as ureteral reimplantation and appendicovesicostomy can be performed (intravesically or extravesically) at the same time. Lastly, it is important to note that autoaugmentation does not preclude further augmentation procedures if unsuccessful.

\subsubsection{Disadvantages}

The major drawback of autoaugmentation is that clinical experience has failed thus far to identify the most appropriate patients for this procedure. Mixed results have been obtained clinically with regard to symptomatic and postoperative urodynamic improvement in the autoaugmented bladder. Evaluations of the available data indicate that there is no direct correlation between preoperative urodynamic findings and future success. It works well in some patients while it fails in others. It is of note that many patients have demonstrated clinical improvement after these procedures without a significant change in urodynamics. The exact reasons for the improvement are unknown.

Another drawbacks of autoaugmentation is a limited increase in bladder capacity. Landa and Moorhead (1994) noted that if the maximum capacity and the volume of urine held at $40 \mathrm{~cm}$ $\mathrm{H}_{2} \mathrm{O}$ are similar, the patient may be better served by immediate intestinal cysloplasty.. The patient and surgeon must be prepared for such an event on occasion. Even if adequate expansion is achieved initially, there is concern that any improvement may not last in the long term. In animals, the surface area of the autoaugmentation site was observed to decrease by approximately $50 \%$ at 12 weeks. Progressive thickening and contractor of the site because of collagenous infiltrate was noted. Almost one-half of is adult patients with hyperreflexia who early on had a good result after autoaugmentation failed with longer follow-up (79).

An additional concern with autoaugmentation is the theoretical increased risk of bladder rupture that has been demonstrated in animal studies. Although perforation of the autoaugmented bladder has been reported in one patient, the overall increased risk of bladder rupture as compared to other types of bladder augmentation has yet to be defined (83).

Inadvertent opening of the mucosa during the procedure can make subsequent mobilization more difficult and may promote prolonged postoperative extravasation. Such extravasation usually stops with bladder drainage. Prolonged drainage, however, may lead to compromised results due to collapse of the diverticulum. If concomitant ureteral reimplantation or bladder neck surgery is necessary, various authors have recommended that such procedures should be done first with the bladder then closed before detrusorectomy.

\subsubsection{Patient selection for autoaugmentation}

Leng and associates (1999), reported good results with the technique among patients with hyperreflexia(85). Adequate preoperative volume may be the most important predictor of success. Autoaugmentation probably should be considered only in patients who have reasonable capacity but poor compliance due to uninhibited contractions(82). If a remarkable increase in capacity is needed, autoaugmentation is unlikely to be as definitive as other techniques. However, it should be noted that autoaugmentation has been successful in some patients with a small capacity, poorly compliant bladder. 


\subsection{Seromuscular grafts and de-epithelialized bowel segments \\ 5.2.1 Technical considerations}

Seromuscular grafts and de-epithelialized bowel segments, either alone or over a native urothelium have been attempted $(24,86)$. The concept of demucosalizing organs is not new to urologists. More than four decades ago, in 1961, Blandy proposed the removal of submucosa from intestinal segments used for augmentation cystoplasty to ensure that mucosal regrowth would not occur (13).

Hypothetically, this would avoid the complications associated with use of bowel in continuity with the urinary tract. Since Blandy's initial report, 25 years transpired before there was a renewed interest in demucosalizing intestinal segments for urinary reconstruction $(87)$.

Several other investigators have pursued this line of research $(24,86,88)$. These investigative efforts have emphasized the complexity of both the anatomic and cellular interactions present when tissues with different functional parameters are combined. The complexity of these interactions is emphasized by the observation that the use of demucosalized intestinal segments for augmentation cystoplasty is limited by either mucosal regrowth or contraction of the intestinal patch ${ }^{88}$.

It has been noted that removal of only the mucosa may lead to mucosal regrowth, whereas removal of the mucosa and submucosa may lead to retraction of the intestinal patch (89).

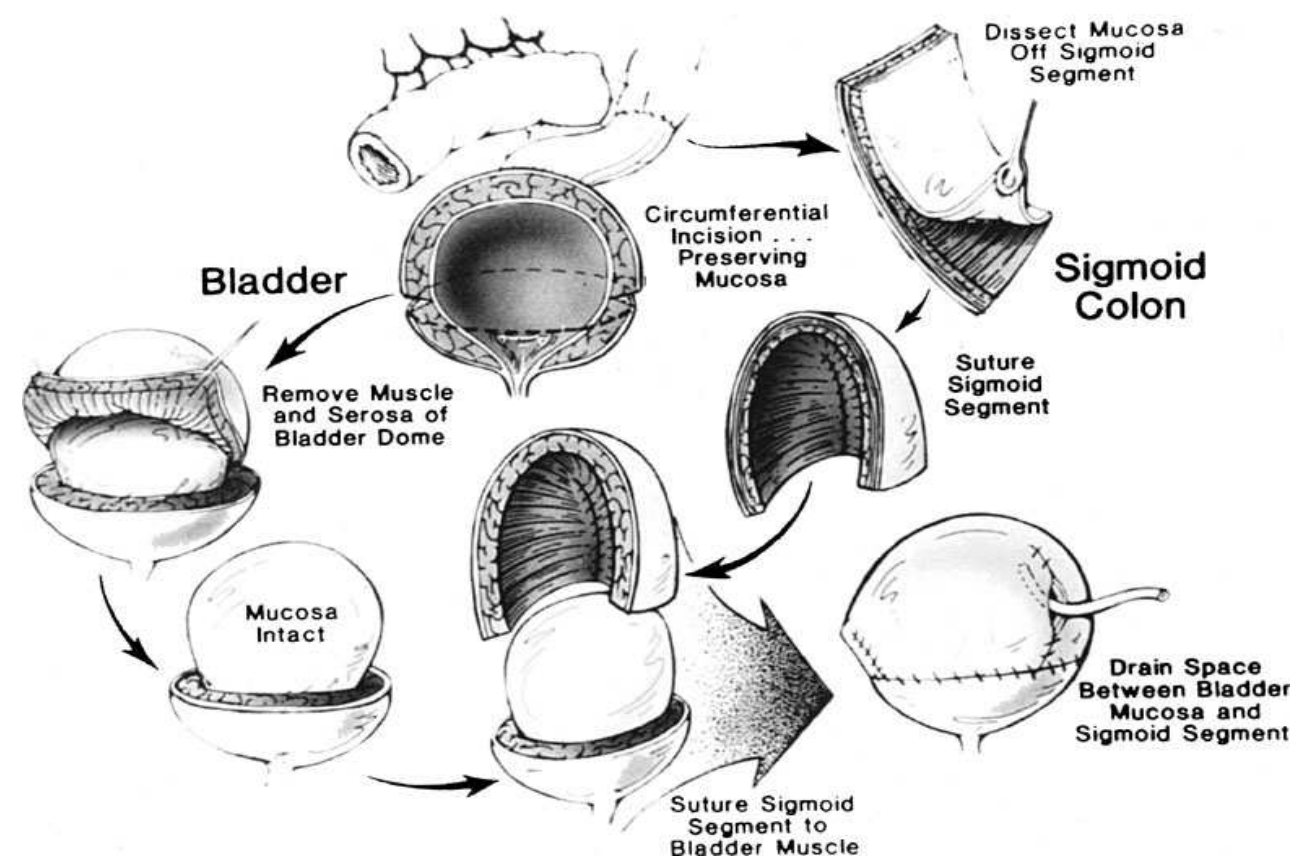

Seromuscular enterocystoplasty using sigmoid colon (SCLU). Detrusor incision is performed similar to autoaugmentation; however, the bulging mucosa is covered with a demucosalized segment of sigmoid colon. (From Buson H, Manivel JC, Dayanc M, et al: Seromuscular colocystoplasty lined with urothelium: Experimental study. Urology 1994;44:745. 
Seromuscular enterocystoplasty combines autoaugmentation with a demucosalized flap of colon or stomach. The removal of the gastrointestinal mucosa results in a denuded seromuscular flap that can be placed over the exposed bladder mucosa of an autoaugmented bladder to avoid collagen deposition and contraction. This combination has been done to potentially preserve the advantages of both procedures.

\subsubsection{Results}

The clinical results of seromuscular enterocystoplasty have been mixed and unpredictable. Initial reports by Dewan and Gonzales in both animal models and humans have been encouraging $(24,86)$. In the Gonzales et al series of 16 patients undergoing seromuscular colocystoplasty utilizing sigmoid colon, bladder capacity was increased to almost two and one half times the preoperative volume and end filling-pressures decreased by approximately 50 percent in 14 patients. Two patients failed and required ileocystoplasty their urodynamic data were excluded. Two other patients developed an hourglass deformity (24). Endoscopic biopsy of the segments was interesting: of 10 biopsies in the series, 1 revealed urothelium with islands of colonic mucosa, and 2 others found only colon mucosa. Removal of all of the enteric mucosa is important when using sigmoid to prevent mucoceles or overgrowth of intestinal mucosa (24).

Dewan and associates (1997) reported on five patients undergoing seromuscular gastrocystoplasty. Four of the five patients have had urodynamic evidence of improved bladder capacity and compliance during the first postoperative year. They believed that preservation of the submucosa eventually promoted regrowth of bowel mucosa. The interaction of the two different tissues will be interesting to follow. The long-term effects on the urothelium by the seromuscular segment and vice versa are unknown. Work has shown that persistent transitional lining will protect from metabolic problems and mucus production $(24,86)$.

Despite these initial encouraging results, it is important to note that the follow-up in these series has been relatively short and approximately 25 percent of patients have eventually required a secondary operation due to either complication related to the seromuscular flap (contracture) and/or failure to adequately improve bladder capacity and/or compliance (86). A more recent report of long-term follow-up of 13 patients after seromuscular gastrocystoplasty by Carr et al (1999) describes variable results, at best. The mean follow-up was 50 months. Five patients had a good outcome with regard to objective urodynamic and subjective clinical improvement. Four patients were found to have a "fair" outcome in that they had some objective improvement, while the remaining four patients had a poor result and required re-augmentation (90). Evaluation of preoperative urodynamic and radiographic data in these patients again demonstrated that it was not possible to predict preoperatively which patients would do well after seromuscular gastrocystoplasty. These procedures are technically more demanding than simple augmentation or autoaugmentation and are associated with more blood loss and a longer operative time (24). Increased bleeding is particularly likely when using stomach.

These urothelium-lined, seromuscular augmentations are theoretically attractive. Thus far, the failure and reoperation rate after such procedures remains higher than that noted for standard enterocystoplasty (90). The best results have been reported with the use of colon. Those results may be partially attributed to the learning curve with a new, complex procedure. Longer follow-up and more experience arc necessary to determine whether the complication rate will decrease with experience or increase because of problems with the combination. 
In summary, seromuscular enterocystoplasty appears to parallel autoaugmentation that is technically feasible and useful in many patients. However, it has significant shortcomings. It is not possible at this time to define which patients will succeed and which ones will fail. Advantages beyond autoaugmentation appear to be minimal. Further long-term studies are required to determine the true efficacy of this technique. Also, additional studies are needed to determine if there are significant functional differences between seromuscular colocystoplasty and seromuscular gastrocystoplasty.

\subsection{Ureterocystoplasty}

The use of ureteral tissue for bladder augmentation purposes was first described in 1992 (91). Native ureter is for many reasons the best tissue available for augmentation cystoplasty. It is autologous, lined with urothelium, backed by muscle, distensible, and complaint (92, 93). However, not all patients in need of bladder augmentation have dilated ureteral tissue available for use. Patients that are candidates for ureterocystoplasty should have either i) a nonfunctional renal unit that can be removed making the ureter and renal pelvis available, or ii) a functional renal unit that is associated with a massively dilated, tortuous, and elongated ureter. The lower ureter can then be used for augmentation, while kidney drainage is re-established by reimplantation of the straightened upper ureter into the bladder or by transureteroureterostomy.

An example of an ideal candidate is one with vesicoureteral reflux and dysplasia (VURD) syndrome from posterior urethral valves. In patients with posterior urethral valves, unilateral reflux may behave as a "pop-off" valve to lower intravesical pressures and protect the contralateral upper tract. In many of these patients, the refluxing ureter is massively dilated, draining a poorly functioning or nonfunctioning kidney. It was a logical extension to use this ureteral tissue to augment the bladder. Ureterocystoplasty is also appropriate in patients on dialysis with end-stage renal failure who are awaiting transplantation and are in need of augmentation due to bladder dysfunction.

More recently, the use of ureterocystoplasty has been expanded in an attempt to take advantage of this valuable tissue and make it available to more surgical candidates. Its use has been reported in patients with a duplex system in which either the upper or lower pole is nonfunctioning (96). In patients with a duplex system and a dilated ureter in conjunction with a functioning renal segment, drainage of that segment can be accomplished with an ipsilateral ureteroureterostomy with preservation of the lower portion of the ureter for augmentation. Ahmed et al have also described the "tandem" use of bilateral megaureters for ureterocystoplasty (97).

\subsection{Technical considerations}

Ureterocystoplasty can be performed through a midline, intraperitoneal incision. This incision provides access to the intestine should mobilization of the ureter be unsatisfactory. Ureterocystoplasty may also be done through two incisions, remaining completely extraperitoneal. The general technique is the same. A standard nephrectomy is performed with great care to preserve the renal pelvic and upper ureteral blood supply. All adventitia and periureteral tissue is swept from the peritoneum toward the ureter during mobilization to protect the ureteral blood supply. Proximally, this blood supply typically arises medially. As the ureter enters the true pelvis, the blood supply arises posteriorly and laterally.

After mobilization of the ureter into the pelvis, the bladder is opened in the sagittal plane. Posteriorly, this incision has typically been carried offcenter directly into and through the 
ureteral orifice of the ureter used for cystoplasty. The ureter is not detached from the bladder but is opened longitudinally along its entire length, with care taken to avoid its main blood supply. The incision in the bladder and distal ureter should avoid branches of the superior vesical artery, which serves as an important blood supply to the mobilized ureter. The ureter is folded on itself, and the ureter-to-ureter and ureter-to-bladder anastomoses are performed with running absorbable suture.

Alternatively, the bladder incision can be stopped approximately $2 \mathrm{~cm}$ from the orifice, with a similar length of distal ureter left in situ and intact without incision. The resulting small loop of intact ureter does not create clinical problems or adversely affect the end volume in a significant manner (20). This modification of technique is easier and may be safer in that, it avoids potential injury to the blood supply of the mobilized ureter near the ureterovesical junction.
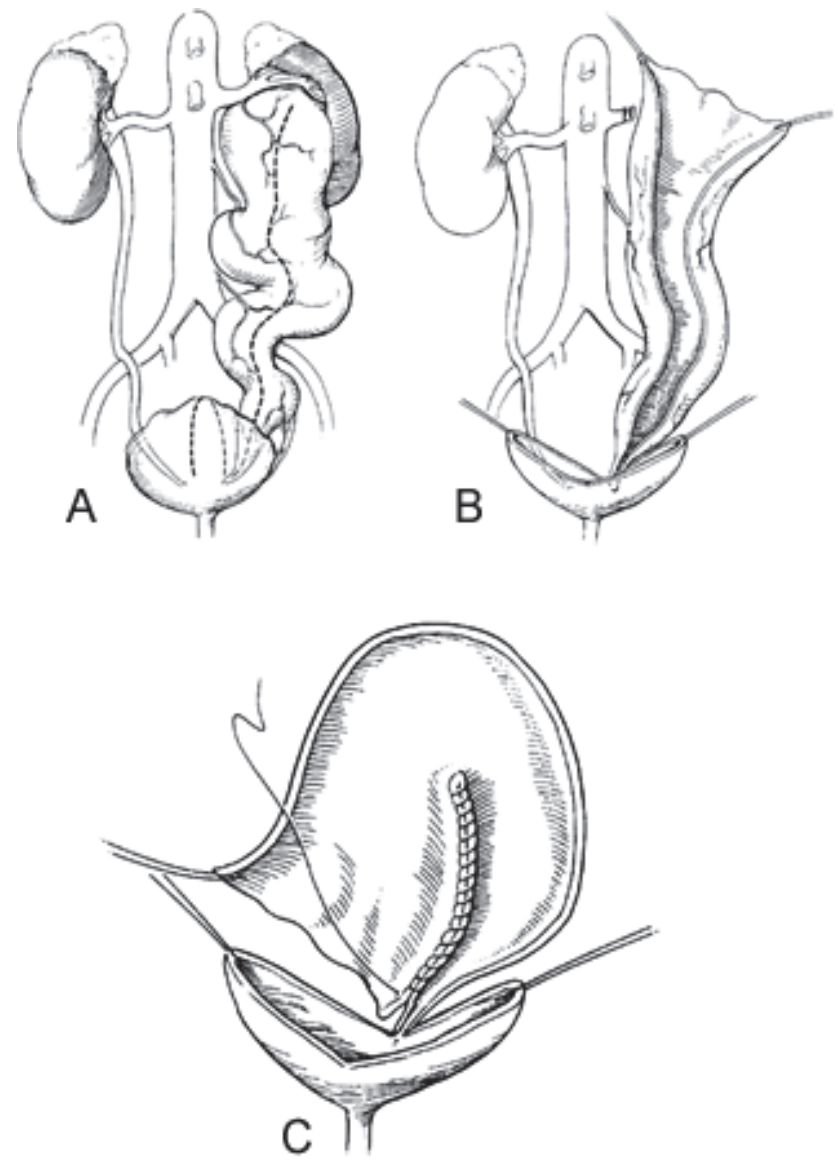

A) A megaureter and poorly functioning kidney are required for ureterocystoplasty.

B) After nephrectomy, the dilated ureter is detubularized, taking care to preserve the blood supply. C) The detubularized ureter is reconfigured before being anastomosed to the bladder (1). 


\subsubsection{Results}

Numerous series have reported good results after augmentation using ureter, some with follow-up as long as 8 years. The upper tracts have remained stable or improved in virtually all patients. Complications have been uncommon, with only a rare early extravasation of urine reported ${ }^{(92)}$.

The largest published series is that of Churchill et al (1993) in which ureterocystoplasty was performed in 16 patients. Thirteen patients had enough urodynamic data available postoperatively for adequate evaluation. Twelve out of thirteen patients had excellent results. As a group, there was a 218 percent increase in bladder capacity, a 284 percent increase in pressure specific bladder capacity, and a 227 percent increase in bladder compliance.

Landau and colleagues (1994), compared age-matched and diagnosis-matched children who underwent ureterocystoplasty or ileocystoplasty. The total mean bladder capacity was 470 $\mathrm{ml}$ in the ureterocystoplasty group and $381 \mathrm{ml}$ in the ileocystoplasty group. Bladder volumes at $30 \mathrm{~cm} \mathrm{H}_{2} \mathrm{O}$ were $413 \mathrm{ml}$ and $380 \mathrm{ml}$ after ureterocystoplasty and ileocystoplasty, respectively. Ureter effectively enhanced both volume and compliance. They reported no significant differences in the postoperative mean increase in bladder capacity and pressure specific bladder volume. Both procedures resulted in excellent functional results (94).

Hitchcock et al (1994) has described similar excellent short-term results in eight patients (95).

\subsubsection{Advantages}

There are several advantages of using the ureter for augmentation. As is the case with autoaugmentation, the major advantage of ureterocystoplasty is that the native urothelium is preserved, thereby avoiding the specific potential problems associated with the use of bowel. Unlike some cases following autoaugmention, the full thickness opened ureter does not tend to shrink with time, unless the vascular supply is compromised. In patients with end-stage renal disease, the procedure can be performed extraperitoneally, thus, preserving the peritoneum for future peritoneal dialysis. When necessary, concomitant procedures in the bladder may also be performed. It seems likely that the risk of tumor formation will be avoided, and perforation of the augmented bladder may be less probable. However, longterm follow-up will be needed to confirm these notions (92). Lastly, there is increased potential for spontaneous voiding postoperatively in patients who are able to empty their bladders adequately preoperatively.

\subsubsection{Disadvantages}

The main disadvantage of ureterocystoplasty is that it is only applicable in a minority of patients. Surgical candidates for ureterocystoplasty include patients with either a nonfunctioning renal unit or a megaureter long enough that ipsilateral renal drainage can be re-established following use of the lower ureter for augmentation (92).

\section{To the future: Tissue expansion for bladder augmentation}

\subsection{The experiments}

In an attempt to make ureterocystoplasty available to make to patients with non-dilated ureters, some have developed methods of producing a dilated ureter. Lailas et al (1996) have demonstrated in a rabbit model that a temporary cutaneous ureterostomy can be used to perform hydrostatic distention of the ureter with subsequent successful ureterocystoplasty. In this study, the ureteral units were dilated at least 10 fold, as measured by radiography, 
after daily injection of a saline-antibiotic solution for 1 month. Augmentation cystoplasty was performed with the reconfigured dilated uretral segment. Repeated cystography and cystometry showed an increased bladder capacity ranging from $190 \%$ to $380 \%$ (98). In a similar system, a dilating catheter was used to dilate tissue in pigs (99).

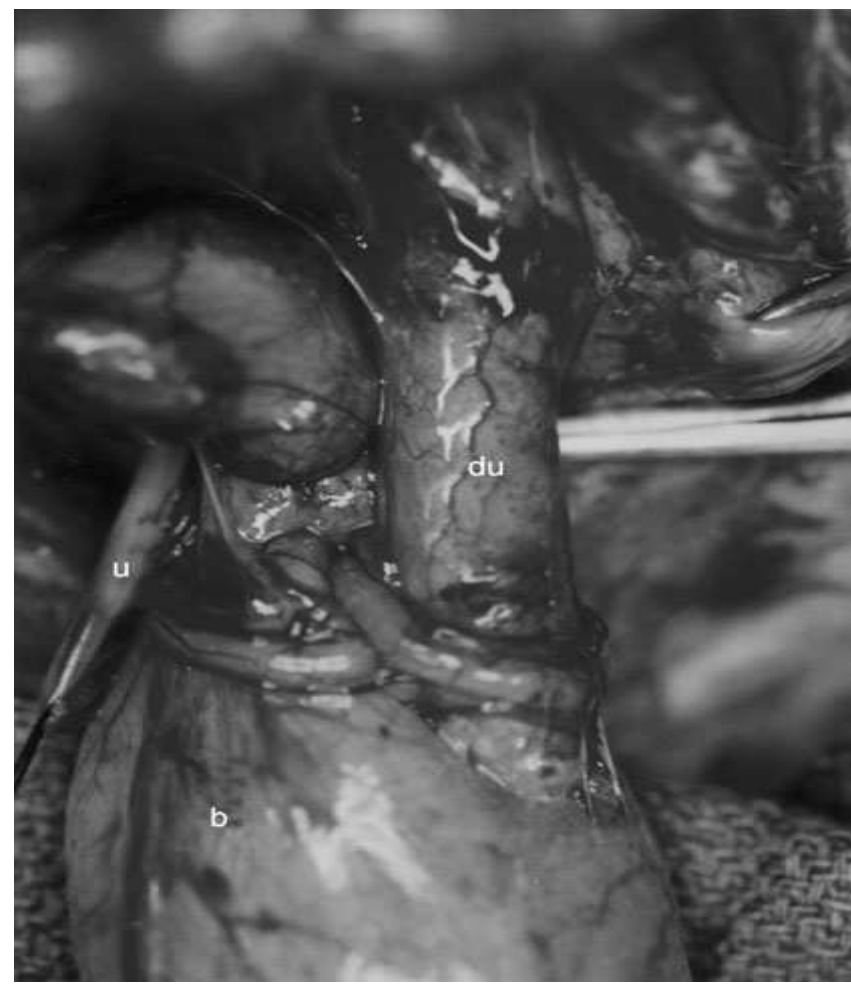

Progressive dilation can be performed in a normal-caliber ureter, which can be subsequently used for ureterocystoplasty. After placement of a ureteral dilation device, comparison is made of progressively dilated ureter $(\mathrm{du})$ and native undilated ureter $(\mathrm{u})$ coming off the bladder (b) (13).

A system for the progressive expansion of native bladder tissue has also been used for augmenting bladder volumes (Satar et al, 1999). Beagle dogs underwent urodynamic studies and the bladders were divided horizontally into two segments: a superior bladder neoreservoir, and an intact smaller bladder inferiorly with both ureters left intact and draining. A silastic catheter was threaded into the newly formed, superiorly located neoreservoir, and connected to an injection port, which was secured subcutaneously. Four weeks after surgery, a saline-antibiotic solution was injected daily into the palpable injection port. Dilating the neoreservoir through the silastic catheter within 30 days after progressive dilation, the neoreservoir volume was expanded at least 10 -fold, as measured by radiography and cystometrography. Urodynamic studies of the dilated neoreservoirs showed normal compliance in all animals. Microscopic examination of the expanded neoreservoir tissue showed a normal histology (100). 

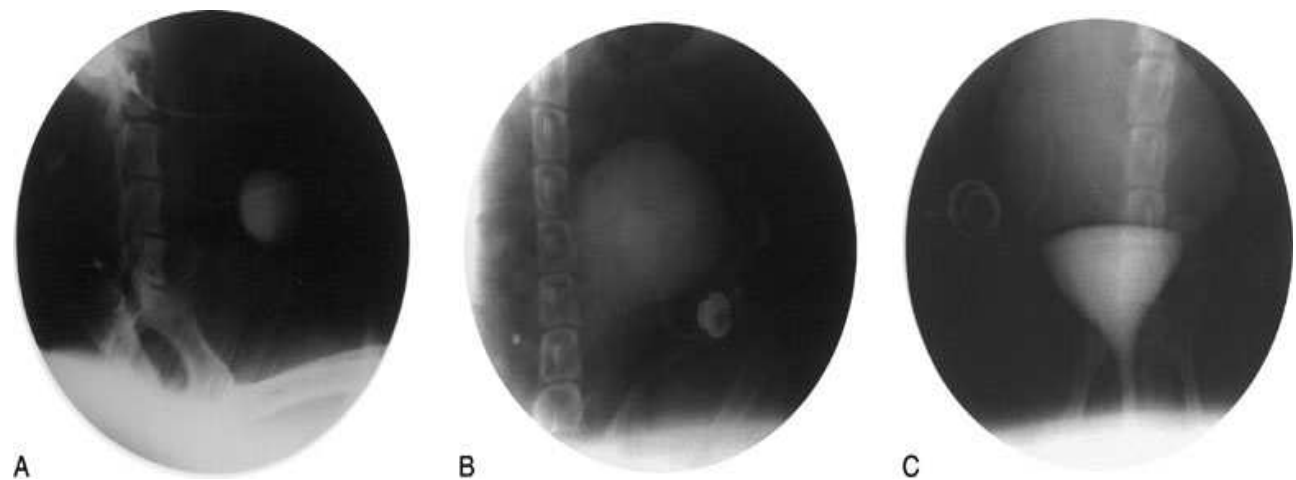

Progressive bladder dilation can be performed with adequate increases in capacity. Cystography of bladder neoreservoir before progressive dilation $(A)$ is compared with cystography results after progressive dilation $(B)$ and with cystogram showing dilated neoreservoir and intact bladder segment $(C)$ (13)

\subsection{The expectations}

Ideally, bladder tissue expansion could be performed with an indwelling dilation catheter, similar to a Foley catheter with a large balloon. In the future, one could foresee placing a dilating catheter intravesically in a patient who either requires augmentation, in an intermittent fashion (e.g. four times daily) or left indwelling. An expanding balloon within the catheter could then be filled progressively, with either continuous or intermittent filling until the desired bladder volume is achieved. Studies associated with this concept are currently being conducted in the laboratory. Clinical application of these interesting ideas has yet to be undertaken (13).

\section{Tissue engineered bladder}

The complications that are associated with using various portions of the gastrointestinal tract for genitourinary reconstruction in both adults and children have stimulated the development of tissue engineering techniques for bladder reconstruction through bladder regeneration. Current research efforts are focused on the development of biodegradable materials which are well-characterized with predictable behavior that can be used as alternatives to gastrointestinal segments for bladder reconstruction.

Tissue engineering follows the principles of cell transplantation, materials science, and engineering toward the development of biologic substitutes that can restore and maintain normal function. Bladder reconstruction via tissue engineering and bladder regeneration involve the use of a biomaterial graft (matrix), either permanent or biodegradable, that will function as a suitable scaffold to allow the body's ability of regeneration and growth to occur either naturally (matrices alone unseeded) or with the addition of cultured cells (matrices with cell - seeded) $(3,101)$.

The ideal graft material is one that would be replaced by the host tissue, provide a lowpressure reservoir, and serve as a scaffold for regeneration of the bladder wall with normal function characteristics. If a suitable graft material can be developed, the need for autogenous tissue and the associated complications of intestinal segments could be 
eliminated. Currently, there are two types of tissue engineering technologies that have preliminarily been shown to induce bladder regeneration. These are the unseeded and seeded technologies (14).

\subsection{Biomaterials}

\subsubsection{Functions}

Biomaterials in genitourinary tissue engineering function as an artificial extracellular matrix (ECM) and elicit biologic and mechanical functions of native ECM found in tissues in the body. Native ECM brings cells together into tissue, controls the tissue structure, and regulates the cell phenotype. Biomaterials facilitate the localization and delivery of cells and/or bioactive factors (e.g. cell adhesion peptides, growth factors) to desired sites in the body; define a three dimensional space for the formation of new tissues with appropriate function. The configuration of the biomaterials can guide the structure of an engineered tissue. The biomaterials provide mechanical support against in-vivo forces of tissue development. The biomaterials can be loaded with bioactive signals, such as cell-adhesion peptides and growth factors, which can regulate cellular function (102).

\subsubsection{Design and selection}

The design and selection of the biomaterial is critical in the development of engineered genitourinary tissues. The biomaterial must be capable of controlling the structure and function of the engineered tissue in a predesigned manner by interacting with transplanted cells and/or host cells. Generally, the ideal biomaterial should be biocompatible, promote cellular interaction and tissue development, and possess proper mechanical and physical properties.

The selected biomaterial should be biodegradable and bioresorbable to support the reconstruction of a completely normal tissue without inflammation. Such behavior of the biomaterials avoids the risk of inflammatory or foreign body responses that may be associated with the permanent presence of a foreign material in the body. The degradation products should not provoke inflammation or toxicity, and must be removed from the body via metabolic pathways. The degradation rate and the concentration of degradation products in the tissue surrounding the implant must be at a tolerable level (103).

The biomaterials need to be processed into specific configuration. A large ratio of surface area to volume is often desirable to allow the delivery of a high density of cells. A highporosity, interconnected pore structure, with specific pore sizes promotes tissue ingrowth from the surrounding host tissue. Several techniques have been developed that readily control porosity, pore size, and pore structure (13).

\subsubsection{Types of biomaterials}

Generally, three classes of biomaterials have been used for engineering of genitourinary tissue: synthetic polymers, such as polyglycolic acid (PGA), polylactic acid (PLA), and polylactic-co-glycolic acid) (PLGA), naturally derived materials, such as collagen and alginate; and cellular tissue matrices, such as bladder submucosa and small-intestinal submucosa. These classes of biomaterials have been tested in regard to their biocompatibility with primary human urothelial and bladder muscle cells. Naturally, derived materials and cellular tissue matrices have the potential advantage of biologic recognition. Synthetic polymers can be produced reproducibly on a large scale with controlled properties of strength, degradation rate, and microstructure (105). 


\subsection{Matrices for bladder regeneration}

\section{A. Unseeded matrices (Acellular)}

The first technique currently being investigated for bladder regeneration is the unseeded technology. This technology involves placement of matrix graft into the wall of the hostbladder. The body then provides the needed environment for subsequent cell growth and tissue regeneration. This represents an unseeded bladder regenerating process.

Thus far, the major obstacle to unseeded tissue engineering technology has been the inability to develop an optimal biomaterial that will act as a suitable scaffold for the "natural" process of regeneration.

\subsubsection{Synthetic non-biodegradable biomaterials}

Synthetic non-biodegradable biomaterials such as silicon, Teflon, rubber, polytetrafluoroethylene, and polypropylene have been tried with unsuccessful results because of host foreign body reactions. Most of these attempts have failed because of mechanical, structural, functional, or biocompatibility problems. Usually, permanent synthetic materials used for bladder reconstruction succumb to mechanical failure and urinary stone formation, and use of degradable materials leads to fibroblast deposition, scarring, graft contracture, and a reduced reservoir volume over time.

\subsubsection{Synthetic biodegradable biomaterials}

As a consequence of these failures with non biodegradable materials, synthetic biodegradable material e.g. collagen and Vicryl (PGA) matrices were developed in the hope that these grafts would allow the host bladder adequate time for regeneration but dissolve prior to sever foreign body reaction. These materials have been used experimentally and have shown less graft encrustation and infectious complications compared to nonbiodegradable materials. However, graft shrinkage still limited potential clinical utility of these materials.

Collagen/Vicryl composite membranes were used as a scaffold for tissue ingrowth to repair a full thickness defect in the bladder of rabbits. The collagen membranes were reinforced with meshes of Vicryl, a biodegradable polimer composed of PLGA, to strengthen the collagen membranes, which are too soft to suture reliably. The results of the initial study were not encouraging because of the occurrence of sever infection (Monsour et al, 1987). However, a later study obtained a high success rate when the experiments were repeated using purification and $\gamma$ irradiation of collagen and postoperative administration of antibiotics. At 3 weeks, a normal urothelium was noted. At 6 weeks, no implanted biomaterial was identified. At 35 weeks, smooth muscle regeneration was evident. During this period, there was no evidence of urinary leakage, infection, or bladder calculi (Scott et al, 1988).

\subsubsection{Natural biodegradable materials}

Collagen based matrices for tissue regeneration such as placenta, amnion and pericardium have been investigated in dogs and have shown clear evidence of bladder regeneration (106, $107,108)$. Functionally, the implanted bladders showed adequate capacity for up to 36 months. Nevertheless, they were observed grossly to undergo graft shrinkage. Histologically, the epithelial layer was present, but the muscular layer was absent.

However, despite initial encouraging results, none of these materials has been found to be suitable for clinical use. The reasons for this are not entirely clear. It can only be speculated 
from the available literature that long-term experimental results with these biodegradable materials did not recapitulate the initial results and therefore clinical trials were not undertaken.

\subsubsection{Acellular Extracellular Matrix (ECM) grafts}

Recently there has been the development of new types of biodegradable materials that have shown tremendous potential for the induction of bladder regeneration with unseeded tissue engineering technology. These materials are acellular extracellular matrix (ECM) grafts that are derived from various different organs. The graft is made acellular by a mechanical process that lyses the cells and/or by detergent and enzymatic extraction. These types of ECM grafts may be xenogenic or allogenic and have been derived from full thickness bladder, stomach, and the submucosal layer of small intestine (109).

\subsubsection{Xeogenic acellular matrix grafts}

Small Intestinal Submucosa (SIS)

The most thoroughly studied collagen based ECM graft for bladder augmentation and urinary reconstruction utilizing unseeded technology is small intestinal submucosa (SIS) (109). SIS is a xenogentic membrane derived from pig small intestine in which the mucosa is mechanically removed from the inner surface and the serosa and muscularies are mechanically removed from the outer surface. This result in a thin, translucent membrane (0.1 mm wall thickness) composed mainly of the submucosal layer of the intestinal wall. Production of SIS is reminiscent of the manufacturing of sausage casing. This unique material has been shown to function well as an arterial or venous graft with rapid replacement by native tissues and evidence of tissue specific regeneration (101).

SIS grafts have been shown to promote full thickness bladder regeneration in both rat and canine animal models. The regenerated bladder tissue is composed of all three layers of the normal bladder wall (urothelium, smooth muscle, and serosa). In addition, the regenerated segment is contractile, compliant, and functionally innervated. Urodynamic studies in a long-term canine augmentation model have demonstrated that the SIS augmented bladder maintains normal bladder capacity and compliance that persist for at least 15 months postoperatively. In vitro muscle strip studies on the regenerated portions of the bladders also demonstrate contractility and compliance that is similar to normal bladder (110).

SIS has been shown to be non-immunogenic with over 1000 cross species transplants and direct challenge testing elucidating no response. In addition, SIS is unique from other biomaterials that have been studied thus far in that it contains a combination of active intrinsic growth factors, cytokines, structural proteins, glyeoproteins, and proteoglycans that may assist in cell migration, cell-to-cell interaction, as well as cell growth and differentiation during the regenerative process. These inherent elements within SIS may prove to be vital to the regenerative process. Further research is needed to identify the functional importance of each of these elements and factors (101).

\subsubsection{Allogenic acellular matrix grafts}

\section{Bladder Acellular Matrix Grafts (BAMG)}

Similar types of cellular ECM grafts to SIS have also been shown to induce bladder regeneration in vivo. Preliminary works have demonstrated that successful morphologic 
and functional regeneration of the rat urinary bladder can be accomplished with homologous bladder acellular matrix grafts (BAMG).

The allogeneic acellular bladder matrix has served as a scaffold for the ingrowth of host bladder wall components in rats. The matrix was prepared by mechanically and chemically removing all cellular components from bladder tissue. Partial cystectomy (25\% to 50\%) was performed, followed by augmentation cystoplasty using acellular bladder matrices. The mucosal lining was complete within 10 days. After 4 weeks, muscular and vascular regeneration was completed. Nerve regeneration continued to improve until week 20 . The grafted bladders had significantly better capacity and compliance than the autoregenterated bladders after partial cystectomy alone. The bladders regenerated with acellular matrix grafts exhibited contractile activity to electric and carbachol stimulation. Clinically relevant antigenicity was not evident. However, there was a $26 \%$ to $36 \%$ incidence of bladder stone formation (111,112).

\section{B. Seeded matrices}

\section{Allogenic Cellular Matrix Grafts}

In multiple studies using various materials as acellular grafts for cystoplasty, the urothelial layer was able to regenerate normally, but the muscle layer, although present, was not fully developed $(111,112,113)$.

Allogenic bladder submucosa preloaded with cells was used as a biomaterial for bladder augmentation in dogs (113). The regenerated bladder tissues contained a normal cellular organization consisting of urothelium and smooth muscle and exhibited a normal compliance. Biomaterials preloaded with cells before their implantation showed better tissue regeneration compared with biomaterials implanted with no cells, in which tissue regeneration depended on ingrowth of the surrounding tissue. The bladders showed a significant increase $(100 \%)$ in capacity when augmented with scaffolds seeded with cells, compared to scaffolds without cells (30\%).

\subsubsection{Summary}

Studies involving acellular matrices that may provide the necessary environment to promote cell migration, growth, and differentiation are being conducted, and demonstrate that bladder regeneration using unseeded tissue engineering technology is feasible without the complications of graft shrinkage, incrustation, and infection. These observations have obvious and significant clinical ramifications. The ability to augment the bladder without the use of bowel or other native host tissue would eliminate many of the complications of conventional enterocystoplasty and would simplify the technical aspects of this operation. Further research into the individual composition of the various biomaterials, the cell-to-cell interaction, and the growth factors that are involved in the bladder regenerative process will be required prior to clinical use of these grafts.

\subsection{Bladder tissue engineering with selective cell transplantation (seeded technology)}

The second type of tissue engineering technology, the seeded technique, involves the use of biodegradable materials that act as cell delivery vehicles for cultured cells from the patient. This technique has been applied to the urinary bladder. Initially, this process is begun by harvesting native bladder tissue for the establishment and expansion of primary cultures of 


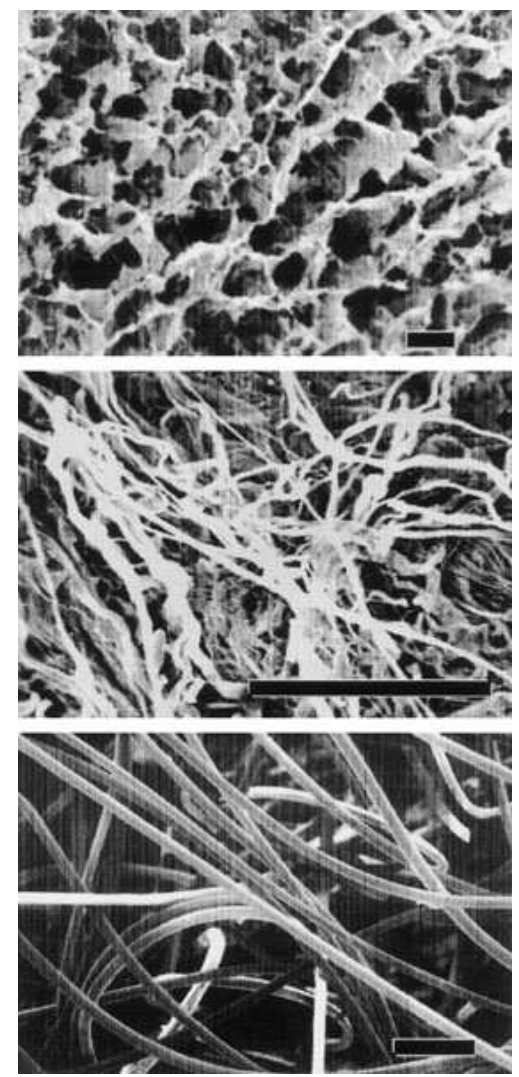

Scanning electron micrographs of biomaterials: collagen sponge (top), acellular matrix prepared from pig bladder submucosa (center), and polyglycolic acid fiber-based matrix (bottom). (Size bars $=100 \mu \mathrm{m}$.) ${ }^{(13)}$.

both bladder smooth muscle and epithelial sells. It is possible to expand a bladder epithelial cell culture from a single biopsy specimen such that the cultured cells could cover a surface area of over $400 \mathrm{~m}$ within eight weeks (14). Once the cells are grown, they are seeded on a biodegradable membrane in vitro and then transplanted back into the host for continuation of the regenerative process.

In 1992, 1993 Atala and associates demonstrated the successful use of non-woven polyglycolic acid polymers sheets, which allow the in-vitro growth of rabbit and human bladder epithelium and smooth muscle cells (114,115). Further work demonstrated that these cell-polymer constructs could be implanted into athymic mice with the subequent formation of organized layers of bladder epithelial and smooth muscle cells.

In these studies, urothelial and muscle cells were expanded in-vitro, seeded onto a polymer scaffold (non-wonen polygycolic acid), and allowed to attach and form sheet of cells. The cell-polymer scaffold was then implanted in-vivo. A series of in vivo urologic associated cell-polymer experiments were then performed. Histologic analysis of human urothelial, bladder muscle, and composite urothelial and bladder muscle polymer scaffold, implanted 
in athymic mice and retrieved at different time points, indicated that viable cells were evident in all three experimental groups (115). Implanted cells oriented themselves spatially along the polymer surfaces. The cell populations appeared to expand from one layer to several layers of thickness with progressive cell organization over extended implantation times. Cell-polymer composite implants of urothelial and muscle cells, retrieved at extended times (50 days), showed extensive formation of multilayered, sheet-like structures and well defined muscle layers. Polymers seeded with cells and manipulated into a tubular configuration showed layers of muscle cells lining the multilayered epithelial sheets. Cell polymers implanted with human bladder muscle cells alone showed almost complete replacement of the polymer with sheets of smooth muscle at 520 days. This experiment demonstrated that composite tissue-engineered structures could be created de novo.

Recently, Yoo et al (1998) and Oberpenning et al (1999), reported on the feasibility of dog bladder augmentation using allogenic bladder submucosa or polyglycolic acid polymers seeded with urothelial and smooth muscle cells (113,116). Organized bladder histology was noted in the regenerated bladder tissue. More importantly, the regenerated bladder tissue was found to increase bladder capacity and was urodynamically compliant.

In order to determine the effect of implanting engineered tissues in continuity with the urinary tract, Yoo and associates (1998), used an animal model of bladder augmentation. Partial cystectomies, which involved removal of approximately $50 \%$ of the native bladder, were performed in 10 dogs. In five, the retrieved bladder tissue was micro dissected and the mucosal and muscular layers separated. The bladder urothelial and muscle cells were cultured. Urothelial and smooth muscle cells were harvested and expanded separately. A collagen-based matrix, derived from allogenic bladder submucosa, was used for cell delivery. This material was chosen for these experiments because of its native elasticity.
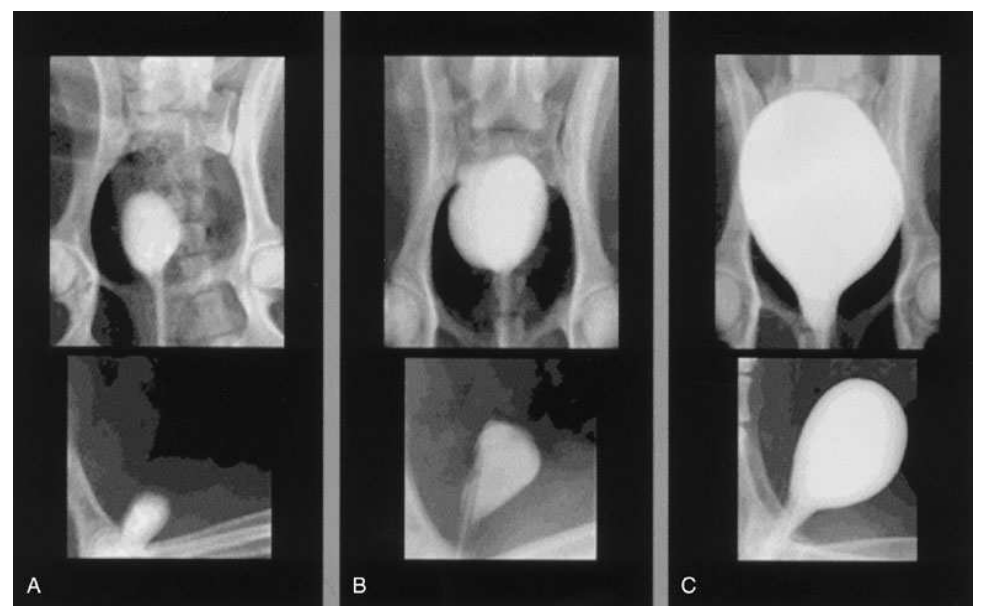

Radiographic cystograms in beagles 11 months after subtotal cystectomy without reconstruction (A); with reconstruction using a polymer without cells $(B)$; and with reconstruction with a polymer and cell-seeded tissue-engineered organ $(C)$. Organs after trigone-sparing cystectomy retained a small-sized reservoir. Tissue-engineered neobladders showed a normal configuration and a larger capacity than the trigones grafted with polymer only (13). 
Within 6 weeks, the expanded urothelial cells were collected as a pellet. The cells were seeded on the luminal surface of the allogenic bladder submucosa and incubated for five days. Muscle cells were seeded on the opposite side of the bladder submucosa. Augmentation cystoplasty was performed with the matrix including cells in one group and the matrix without cells in the second group. The augmented bladders were covered with omentum to facilitate angiogenesis to the implant. Bladders augmented with the matrix seeded with cells showed a 99\% increase in capacity compared with bladders augmented with the cell-free matrix, which showed only a $30 \%$ increase in capacity. Functionally, all animals showed normal bladder compliance as evidenced by urodynamic studies; however, the remaining native bladder tissue may have accounted for these results. Histologically, the retrieved engineered bladders contained a cellular organization consisting of a urotheliumlined lumen surrounded by submucosal tissue and smooth muscle. However, the muscular layer was markedly more prominent in the cell-reconstituted scaffold (113).

\subsubsection{Histologic Parameters of Tissue-Engeneered Bladders}

It has been well established for decades that the bladder is able to regenerate generously over free grafts. Urothelium is associated with a high reparative capacity. Bladder muscle tissue is less likely to regenerate in a normal fashion. Most of the free grafts (without cells) used for bladder replacement in the past were able to show adequate histology in terms of a well-developed urothelial layer, but they were associated with an abnormal muscular layer that varied in terms of its full development. Because native muscle cells are less likely to regenerate over the free grafts, presence of both urothelial and muscle cells on the matrices used for bladder replacement is important for successful tissue bioengineering.

Both urothelial and muscle ingrowth are believed to be initiated from the edges of the normal bladder toward the region of the free graft. Usually, however, contracture or resorption of the graft has been evident. The inflammatory response toward the matrix may contribute to the resorption of the free graft $(89,104)$.

It was hypothesized that building the three-dimensional structure constructs in vitro, before implantation, would facilitate the eventual terminal differentiation of the cells after implantation in vivo and would minimize the inflammatory response toward the matrix, thus, avoiding graft contractor and shrinkage. The study by Yoo and associates (1998) demonstrated a major difference between matrices used with autologous cells (tissueengineered matrices) and those used without cells as regards the graft diameter (113). Matrices implanted with cells for bladder augmentation retained most of their implanted diameter, as opposed to matrices implanted without cells for bladder augmentation, in which graft contraction and shrinkage occurs.

\subsubsection{Functional parameters of tissue-engeneered bladders}

The results of initial studies showed that the creation of artificial bladder may be achieved in vivo; however, it could not be determined whether the functional parameters noted were caused by the augmented segment or by the intact native bladder tissue. To better, address the functional parameters of tissue-engineered bladders; an animal model was designed that required a cystectomy with subsequent replacement organ (116).

A total of 14 dogs underwent a trigone-sparing cystectomy. The animals were randomly assigned to one of three groups. Group A $(n=2)$ underwent closure of the trigone without a reconstructive procedure. Group B $(n=6)$ underwent reconstruction with a cell- free bladder 
shaped biodegradable polymer. Group $C(n=6)$ underwent reconstruction using a bladdershaped biodegradation polymer that delivered autologous urothelial cells and smooth muscle cells harvested from autologous bladder biopsy and expanded.

The cystectomy -only controls and polymer-only grafts maintained average capacities of $22 \%$ and $46 \%$ of preoperative values, respectively. An average bladder capacity of $95 \%$ of the original precystectomy volume was achieved in the tissue-engineered bladder replacements.

The subtotal cystectomy reservoirs that were not reconstructed and the polymer-only reconstructed bladder showed a marked decrease in bladder compliance $(10 \%$ and $42 \%$ total compliance). The compliance of tissue-engineered bladders showed almost no difference from preoperative values. Histologically, the polymer-only bladder presented a pattern of normal urothelial cells with a thickened fibrotic submucosa and a thin layer of muscle fibers. The retrieved tissue- engineered bladders showed a normal cellular organization, consisting of a trilayer of urothelium, submucosa, and muscle. The results from this study showed that it is possible to tissue - engineer bladders that are anatomically and functionally normal (116). Clinical trials for the application of this technology are currently being arranged (116).

Progressive bladder dilation can be performed with adequate increases in capacity. Cystography of bladder neoreservoir before progressive dilation $(A)$ is compared with cystography results after progressive dilation $(B)$ and with cystogram showing dilated neoreservoir and intact bladder segment (C)

\subsubsection{In summary}

It is clear that bladder regeneration is possible utilizing both unseeded and seeded tissueengineering technologies. Further advances in our current techniques will eventually revolutionize urologic reconstructive surgery, as we know it today. It is important to note that all of the animal studies performed thus far have been in animals with a normal bladder. It is not known whether normal or abnormal bladder regeneration can be achieved with either unseeded or seeded technology in an animal or patient with a neuropathic bladder. Active research is currently investigating this vital question. Additionally, studies are needed to better understand the differences that exist between the unseeded and seeded approaches and the resultant regenerated bladder, so that unseeded and aspect approaches and the resultant regenerated bladder so that the best aspects of each technology may be utilized to achieve a superior result. It is the authors' opinion that future chapters on bladder augmentation will discuss the use of intestinal segments as historical footnote while the major focus will be on the indications and methods for various types of tissue engineering technology.

\section{Laparoscopic augmentation cystoplasty}

\subsection{Laparoscopic enterocystoplasty \\ 8.1.1 Patient selection}

Laparoscopy has distinct advantages when compared with open surgical procedures, such as decreased postoperative pain and morbidity, improved cosmoses, a shorter hospital stay, and decreased convalescence. Recent studies have indicated that postoperative intraabdominal adhesions are reduced significantly after laparoscopic surgery when compared with open surgery (117). 


Alternative
Ureter
Autoaugmentation
(bladder myomectomy)

Demucosalized intestinal flap on urothelium (colon, DAWG)

Bladder regeneration on substrate (SIS)

Tissue engineering

\section{Advantages}

1. Urinary epithelium, no mucus

2. Good compliance

1. Urinary epithelium, no mucus

2. Relatively easy, no bowel resection

1. Urinary epithelium, decreased mucus

2. More physiologic

1. No bowel resection

2. Easily performed

1. Bladder regrowth in laboratory

2. Potentially unlimited capacity, no mucus

\section{Disadvantages}

1. Only applicable if the patient has a dilated ureter

2. Ureter may be scarred (reflux, infection)

1. Inconsistent results can result in bladder scarring 2. Sometimes difficult (bladder scarring or diverticula)

1. Difficult procedure

2. Inconsistent results

1. Unproven in children

2. Dependent on native bladder potential for regeneration

1. Unproven in children

2. Dependent on vascular and nerve ingrowth

DAWG, demucosalized augmentation with gastric segment.

Alternatives to intestinocystoplasty

Despite the established role of laparoscopy in diagnostic and ablative urologic surgery, the use of laparoscopic techniques in reconstruction has been limited because of the technical complexity of the procedures involved. The technical steps in performing laparoscopic bladder augmentation are designed to emulate the open surgical counterpart in every aspect, thereby producing similar functional results with an improved recovery.

A relative contraindication specific to laparoscopic bladder augmentation is the presence of extensive intra-abdominal and pelvic adhesions that would preclude laparoscopic dissection. Patients with ventriculo-peritoneal shunts, as noted in cases of myelomeningocele, have increased abdominal adhesions that may preclude a successful laparoscopic approach (117).

\subsubsection{Technical considerations}

Important elements of the operation include:

- Cystoscopic placement of ureteric catheters (optional).

- Transperitoneal placement of 4 to 5 redially arranged trocars. 
- Identification of the cecum and ileocecal junction.

- A 5-mm laparoscope can be introduced through the lower left port to transilluminate the mesentery and identify its vascular pedicle.

- Bowel segment selection and mobilization sufficient for pelvic placement.

- Exteriorizing the bowel loop outside the abdomen through a 2-cm extension of the umbilical port site, preventing twisting of the mesenteric vessels;

- Using traditional open surgical techniques, the bowel segment is isolated, bowel continuity is re-established, mesenteric window is closed, the bowel segment is detubularized along its antimesenteric border and reconfigured (117,118).

- Alternatively, bowel division and side-to-side anastomosis may be done intracorporeally using endoscopic gastrointestinal stapling device with detubularization and freehand intracorporeal suturing to reconfigure the bowel (119).

- Incising the peritoneum, entering the space of Retzius, mobilization of the bladder.

- Vertical incision creating a large cystotomy (bivalving).

- Mobilization of the bowel patch, and fixing it at 6 and 12-o' clock positions.

- Circumferential completion of enterovesical anastomsis in quadrants intracorporeally with running sutures.

\subsubsection{Results}

Hedican and associates (1999) performed laparoscopic assisted bladder augmentation in eight patients. In addition to using a bowel segment for augmentation, in many of these cases they were also able to laparoscopically mobilize the appendix to perform a Mitrofanoff continent catheterizable stoma. They described using both ileum and cecum as the enteric patch for the bladder. The bladder augmentation was done through a low Pfannenstiel incision. Many of these patients were children and this allowed a rapid recovery with decreased pain as well as a good cosmetic result (120).

Gill and associates (2000) underwent laparoscopic enterocystoplasty for three patients with functionally reduced bladder capacities due to neurogenic causes: ileocystoplasty $(n=1)$, sigmoidocystoplasty $(n=1)$, and cystoplasty with cecum and proximal ascending colon $(n=1)$. In all patients, bowel reanastomosis was performed by exteriorizing the bowel loop outside the abdomen. All three laparoscopic enterovesical anastomoses were water tight without postoperative urinary extravasation. The operative times were 5.3, 8, and 7 hours. The hospital stay was 7, 5, and 4 days (118).

Rackley and associates (2001) performed laparoscopic enterocystoplasty in 12 patients with functionally reduced bladder capacities owing to neurogenic causes. Procedures included ileocystoplasty (2), sigmoidocystoplasty (2), colocystoplasty (1), and cecocolocystoplasty with continent catheterizable ileal stoma (7). Total surgical time ranged from 5.3 to 8 hours (average 7.0 hours). The time of laparoscopic suturing ranged from 1.7 to 3.1 hours (average 2.4 hours). Blood loss was minimal and did not exceed $250 \mathrm{ml}$ during any of the procedures (average $175 \mathrm{ml}$ ). The only intra-operative complication was a trocar-induced rectus sheath hematoma. Oral feeding was resumed by 24 hours in 11 of the 12 patients. The average hospital stay was 5.7 days and ranged from 3 to 7 days (117).

Unlike the previously published reports, where portions of the procedure were performed extracorporeally, Elliott and associates (2002) reported their technique of complete laparoscopic ileocystoplasty (119). 


\subsection{Laparoscopic autoaugmentation}

Ehrlich and Gershman (1993), reported the first laparoscopic autoaugmentation in an 8years-old child with a neurogenic bladder. In this case, the procedure required $70 \mathrm{~min}$, follow-up of the patient at 1 year, documented improvement in his symptoms with rare incontinence (121).

In 1995, McDougall and colleagues described the initial laparoscopic retropubic autoaugmentation of the bladder in an adult (12). In this case, the extraperitoneal approach was used and the incision was made in the detrusor muscle leaving the mucosa intact. There was a significant drop in bladder pressure. At the 6-month follow-up, the bladder capacity increased from $85-350 \mathrm{ml}$. However, in a second case, while the procedure could be successfully completed, the long-term result was unsatisfactory.

Due to the success of enteric augmentation and the variable results with autoaugmentation, this procedure has largely fallen into disuse (122). Nevertheless, laparoscopic retropubic autoaugmentation allows a brief hospital stay and minor postoperative discomfort. Moreover, the laparoscopic approach should not complicate or preclude subsequent enterocystoplasty if necessary (123).

\section{Conclusion}

Laparoscopic enterocystoplasty is technically feasible and successfully emulates the established principles of open enterocystoplasty while minimizing operative morbidity. As is true in open surgery, various bowel segments can be fashioned and anastomosed to the bladder laparoscopically. The increased costs associated with laparoscopy and weight minimally invasive surgery in general have been a significant disadvantage; however, a pervious report on the costs of laparoscopic procedures concluded that increased surgical experience reduces the surgical time and length of hospital stay, thereby decreasing costs. Furthermore, the increased use of reusable instruments results in considerable economic benefits. Implementation of appropriate cost-saving strategies ultimately will result in decreased expenses associated with laparoscopy. Although laparoscopic enterocystoplasty is currently a lengthy procedure lasting twice as long as open surgery, further technical modifications and increasing experience will continue to reduce the surgical time involved. For patients with complex co-morbid illness who desire the improved quality of life associated with traditional augmentation cystoplasty, the reduced morbidity observed in the authors' series of patients undergoing a laparoscopic procedure makes this approach an attractive option to consider. The authors' initial experience suggests that laparoscopic enterocystoplasty has the potential to become a viable alternative to open enterocystoplasty.

\section{References}

[1] Mitchell ME, Plaire JC: Augmentation cystoplasty. In Gillenwater JY, Grayback JT, Howards SS, Mitchell ME (eds): Adult and Pediatric Urology. Philadelphia, Lippincot Williams and Wilkins, 2002, P. 2445.

[2] Lapides J, Diokno Ac, Gould FR, et al. Further observations of self - catheterization. J Urol 1976; 116: 169.

[3] Hendren WH, Hendren RB. Bladder augmentation: experience with 129 children and young adults. J Urol 1990; 144: 445. 
[4] Mitchell ME, Piser JA. Intestinocystoplasty and total bladder replacement in children and young adults: follow-up in 129 cases. J Urol 1987; 138: 579.

[5] Nguyen DH, Mitchell ME. Gastric bladder reconstruction. Urol Clin North Am 1991; 18: 649.

[6] Bellinger MF. Urterocystoplasty. Curr Surg Tech Urol 1995; 8: 2.

[7] Cartwright PC, Snow BW. Bladder augmentation: early clinical experience. J Urol 1989; 142: 505.

[8] Cartwright Pc, Snow BW. Bladder augmentation: partial detrusor excision to augment the bladder without use of bowel.1 J Urol 1989; 142: 1050.

[9] Dewan PA, Nicholls EA, Goth DW. Ureterocystoplasty: an extraperitoneal urothelial bladder augmentation technique. Eur Urol 1994; 2685.

[10] Ikeguchi HW, Stifelman MD, Hensle TW. Ureteral tissue expansion for bladder augmentation. J Urol 1998; 159: 1665.

[11] Kropp BP, Sawyer BD, Shannon HE, et al. characterization of small intestine submucosa regenerated canine detrusor: assessment of reinnervation in vitro compliance and contractility. J Urol 1996; 156: 599.

[12] Pope JC, Davis MM, Smith ER, et al. ontogeny of canine small intestine submucosa regenerated bladder. J Urol 1997; 158: 105.

[13] Atala A: Tissue Engineering Perspectives for reconstructive surgery. In Walsh PC, Retick AB, Vaughan ED, Jr, Wein AJ (eds); Campbell's Urology. Philadelphia, WB Sauders, 2002, P. 2523.

[14] Colvert JR, Kropp BP, Cheng EY: Bladder augmentation: Current and future techniques. AUA update series 2003: 22 (32) - 250.

[15] DeMarco RT, Koch MO: Metabolic complications of continent urinary diversion AUA update series: 22 (15) - 114.

[16] Hinman F Jr. Selection of intestinal segments for bladder substitution: physical and physiological characteristics. J Urol 1988; 139: 519.

[17] Koff SA. Guidelines to determine the size and shape of intestinal segments used for reconstruction. J Urol 1988; 140: 1150.

[18] Goldwasser B. Barrett DM, Webster GD, et al: Cystometric properties of ileum and right colon after bladder augmentation. Substitution or replacement. J Urol 1987: 138: 1007.

[19] Adams MC, Mitchell ME, Rink RC. Gastrocystoplasty: An alternative solution to the problem of urological reconstruction in the severely compromised patient. J Urol 1988; 140: 1152.

[20] Adams MC, Brock JW, Pope JC, et al. Ureterocystoplasy: is it necessary to detubularize the distal ureter? J Urol 1998; 160: 851.

[21] Gonzalez R, Cabral BHP. Rectal continence after enterocystoplasty. Dialysis Pediatr Urol 1987; 10 (12): 3.

[22] Abol-Enein H, Ghoneim MA: A novel uretero-ileal reimplantation technique: the serous lined extramural tunnel. A preliminary report. J Urol 1994; 151: 1193.

[23] Mitchell ME: Use of Bowel in undiversion. Urol Clin North Am 1986; 13: 349.

[24] Gonzalez R. Buson H. Reid C, Reinbert Y: Sermoucular colocystoplasty lined with urothelium: experience with 16 patients. Urology 1994; 45: 124-129. 
[25] King LR: Cystoplasty in children. In King LR, Stone AR, Webster GD (eds): Bladder Reconstruction and Continent Urinary Diversion, 2nd ed. St. Louis, Mosby - Year Book, 1991, 115-125.

[26] Cain MP, Husmann DA: Cecal bladder augmentation with a tapered catheterizable stoma: A modification of the Indiana pouch. Presented at the Urology Section Meeting. American Academy of Pediatrics. Dallas. TX, 1994.

[27] Cain MP, Casale AJ, King SJ, Rink RC: Appendicoversicostomy and newer alternatives for the Mitrofanoff procedure: Results in the last 100 patients at Riley children's Hosptial. J Urol 1999; 54: 909-912.

[28] Leong CH: The use of gastrocystoplasty. Dialog Pediatr Urol 1988; 11: 3-5.

[29] Adams MC, Mitchell ME, Rink PC: Gastrocystoplasty: An alternative solutioni to the problem of urological reconstruction in the severely compromised patient. J Urol 1988; 140: 1152-1156.

[30] Mitchell ME, Rinck RC, Adams MC: Augmentation cystoplasty, implantation of artificial urinary sphincter in men and women, and reconstruction of the dysfunction urinary tract. In Walsh PC, Retik AB. Stamey TZ, Vaughn ED, (eds): Campbell's Urology, 6th ed. Philadelphia. WB Saunders, 1992, pp 2630-2653.

[31] Raz S, Ehrilich RM, Babiarz JW, et al: Gastrocystoplasty without opening the stomach. J Urol 1993; 150: 713-715.

[32] Reinberg Y, Manivel JC, Froemming C, et al: Perforation of the gastric segment of an augmented bladder secondary to peptic ulcer disease. J Urol 1992: 148 (2 pt 1). 369371.

[33] Sheldon CA, Gibert A, Wacksman J, et al: Gastrocystoplasty: Technical and metabolic characteristics of the post versatile childhood bladder augmentation modality [see comments]. J Pediatr Surg 1995: 30 (2): 283-287: discussion 287-288.

[34] Kajbafzadeh AM, Quinr. FM, Duffy PG, et al: Augmentation cystoplasty in boys with posterior urethral values. J Urol 1995: 154 (2 pt 2): 874-877.

[35] Docimo SG, Moore RG, Adams J, et al: Laparoscopic bladder augmentation using stomach. Urol 1995: 46 (4): 565-569.

[36] Kurzock EA, Baskin LS, Kogaa Ba: Gastocystoplasty: Is there a consensus? World Urol 1998: 16 (4): 242-250

[37] Kurzrock EA, Baskin LS. Kogan BA: Gastrocystoplasty: long-term follow up. J Urol 1998. 160 (6 pt 1): 2182-2166.

[38] Atala A, Bauer SB, Hendren WH, et al: The effect of gastric augmentation on bladder function. J Urol 1993: 149: 1099-1102.

[39] Gosalbez R, Woodard JR, Broecher BH, et al: The use of stomach in pediatric urinary reconstruction. J Urol 1993. 150 (2 pt 1): 438-440.

[40] Goldwasser B, Webster GD: Augmentation and substitution enterocystoplasty. J Urol 1986; 138, 215-224.

[41] Rink RC, Mclaughlin KP: Indication for enterocystoplasty and choice of bowel segment. Probl Urol 1994; 8: 389-403.

[42] Studer UE, Zingg EJ: Ileal orthotopic bladder substitutes: What we have learned from 12 years, experience with 200 patients. Urol Clin North Am 1997; 24: 781-793.

[43] Shekarriz B, Upadhyay J, Demirbilek S, et al: Surgical complications of bladder augmentation: Comparison between various enterocystoplasties in 133 patients. Urology 2000; 55: 123-128. 
[44] Lytton B, Green DF: Urodynamic studies in patients undergoing bladder replacement surgery. J Urol 1989; 141: 1984.

[45] Jakobsen H, Steven K, Stigsby B, et al: Pathogensis of nocturnal urinary incontinence after ileocecal bladder replacement: continuous measurement of urethral closure pressure during sleep. Br J Urol 1987; 59: 148-152.

[46] Hedlund H, Lindstrom K, Mansson W: Dynamics of a continent Cecal reservoir for urinary diversion. Br J Urol 1984; 56: 366-372.

[47] Thuroff JW, Alken P, Reidmiller H, et al: 100 cases of Mainz pouch: Continuing Experience and evolution. J Urol 1988: 140: 283.

[48] Sidi AA, Reinberg Y, Gonzalez R: Influence of intestinal segment and configuration on the outcome of augmentation enterocystoplasty. J Urol 1986b; 136: 1201-1204.

[49] Berglund B, Kock NG, Norlen L, Philipson BM: Volume capacity and pressure characteristics of the continent ileal reservoir used for urinary diversion. J Urol 1987; 137: 29.

[50] Adams MC, Bihrle R, Rink RC: The use of stomach in urologic reconstruction. AUA Update Series 1995; 27: 218-223.

[51] Rink RC, Hollensbe D, Adams MC: complications of augmentation in children and comparison of gastrointestinal segments. Americal Urological association Update series 1995: 14: 122-128.

[52] Mitchell ME, Piser JA: Intestinocystoplasty and total bladder replacement in children and young adults: Follow-up in 129 cases. J Urol 1987; 138: 579-584.

[53] Roth S, Semjonow A, Waldner M, Hertle L: Risk of Bowel dysfunction with diarrhea after continent urinary diversion with ileal and ileocecal segments. J Urol 1995; 154: 1696-1699.

[54] Smith RB, Can Cangh P, Skinner DG, et al. Augmentation enterocystoplasty: a critical review. J Urol 1977; 118: 799.

[55] Rogers E, Scardino PT: A simple ileal substitute bladder after cystectomy: Experience with a modification of the Studer pouch. J Urol 1995; 153: 1432-1438

[56] Pannek J, Haupt G, Schulze H, et al: Influence of continent ileal urinary diversion on vitamin B12 absorption. J Urol 1996; 155: 1206-1208.

[57] Mills RD, Studer UE: Metabolic consequences of continent urinary diversion. J Urol 1999; 161: 1057-1066.

[58] Koch MO, McDougal WS, Thomson CO: Mechanisms of solute transport following urinary diversion through intestinal segments: An experimental study with rats. J Urol 1991; 146: 1390-1397.

[59] Poulsen AL, Steven K: Acid - base metabolism following bladder substitution with the ileal urethral Kock reservoir. Brit J Urol 1996; 78: 47-53.

[60] Hall MC, Koch MO, Halter SA, et al: Morphologic and functional alterations of intestinal segments following urinary diversion. J Urol 1993; 149: 664-666.

[61] Stein R. Fisch M, Ermert A, et al: Urinary diversion and orthotopic bladder substitution in children and young adults with neurogenic bladder: A safe option for treatment? J Urol 2000; 163: 568-573.

[62] Kock MO, McDougal WS, Reddy PK, et al: Metabolic alterations following continent urinary diversion through colonic segments. J Urol 1991; 145: 270-273. 
[63] Kavaggia FF,Thompson JS, Schaefer EC, et al: Hyperammonemic encephalopathy in urinary diversion with urea-splitting urinary tract infection. Arch intern Med 1990; 150 (11): 2389-2392.

[64] Hessain M: The osteomalaica syndrome after colocystoplasty: A cure with sodium bicarbonate alone. Brit J Urol 1970; 42: 243-245.

[65] Wagstaff KE, Woodhouse CRJ, Rose GA, et al: Blood and urine analysis in patients with intestinal bladders. Brit J URol 1991; 68: 311-316.

[66] Mundy AR, Nurse DE: Calcium balance, growth and skeletal mineralizatin in patients with cystoplasties. Brit J Urol 1992; 69: 257-259.

[67] Palmer LS, Franco I, Koan SJ, et al: Urolithiasis in children following augmentation cystoplasty. J Urol 1993; 150: 726.

[68] Husman DA, Spence HM: Current status of tumor of the bowel following ureterosigmoidostomy: A review. J Urol 1990; 144: 607.

[69] Teriger BFG, Marshall FF: Carcinogenesis and the use of intestinal segments in the urinary tract. Urol Clin North Am 1991; 18: 737.

[70] Filmer RB, Spencer JR: Malignancies in bladder augmentations and intestinal conduits. J Urol 1990: 143: 671.

[71] Little JS, Klee LW, Hoover DM, Rink. RC: long-term histopathologic changes observed in rats subjected to augmentation cystoplasty. J Urol 1994; 152: 720-724.

[72] Carr LK, Herschorn S: Early development of adenocarcinoma in a young woman following augmentation cystoplasty for undiversion. J Urol 1997; 157: 2255-2256.

[73] Barrington JW, Fulford S, Griffiths D, Stephenson TP: Tumors in bladder remnant after augmentation enterocystoplasty. J Urol 1997; 157: 482-486.

[74] Pope JC, 4th, Albers P, Rink RC, Cain MP, et al: Spontaneous rupture of the augmented bladder from silence to chaos. Presented at the European Society of Pediatric Urologists Meeting, Istanbul, Turkey. 1999.

[75] Sheiner JR, Kaplan GW: Spontaneous bladder rupture following enterocystoplasty. J Urol 1988: 140: 1157-1158.

[76] Bauer SB, Hendren WH, Kozakewich H. et al: Perforation of the augmented bladder. J Urol 1992; 148: 699.

[77] Slaton JW, Kropp KA: Conservative management of suspected bladder rupture after augmentation enterocystoplasty. J Urol 1994; 152: 713-715.

[78] Cartwright PC, Snow BW: Bladder augmentation: Partial detrusor excision to augment to bladder without use of bowel. J Urol 1989; 142: 1050.

[79] Johnson HW, Nigro MK, Stothers L, et al: Laboratory variables of autoaugmentation in an animal model. Urology 1994; 44: 260-263.

[80] Stohrer M, Goepel M, Krmaer G, et al: Detrusor myectomy (auto augmentation) in the treatment of hyper-reflexive low compliance bladder. Urology 1999; 38: 30-37.

[81] Landa HM, Moorhead JD: Detrusorectomy. Probl Pediatr Urol 1994; 8: 204-209.

[82] Snow BW, Cartwright P: Why bladder autoaugmentation is a good choice for detrusor instability or bladder hyperreflexia. Contemp Urol 1999:11:96-100.

[83] Ahmed S, Sripathi V, Sen S: Perforation of an autoaugmented bladder autougmentation. New Urol Urdyn 199615 (3): 223-233.

[84] Landman J, et al: Laparascopic autoaugmentation of the urinary bladder: Literature review and state of the art. Ped Endo Inno Tech 2000; 4(3): 213-221. 
[85] Leng WW, Blalock HJ, Fredriksson WH, et al: Enterocystoplasty or detrusor myectomy? Comparison of indications and outcomes for bladder augmentation. J Urol 1999; 161: 758-763.

[86] Dewan PA: Autoaugmentation demucosalized enterocystoplasty. World J Urol 1998: 16: 255-261.

[87] Salle JL, Fraga JC, Lucib A, et al: Seromuscular enterocystoplasty in dogs. J Urol 1990; 144: 454-456.

[88] Cheng E, Rento R, Grayhack TJ, et al: Reversed seromuscular flaps in the urinary tract in dogs. J Urol 1994; 152: 2252.

[89] Atala A: Commentary on the replacement of urologic associated mucosa. J Urol 1995: 156:338.

[90] Carr MC, Docimo SG, Mitchell ME: Bladder augmentation with urothelial preservation. J Urol (in press) 1999.

[91] Wolf JS Jr, Turzan CW: Augmentation urelerocystoplasty. J Urol 1993: 149(5): 10951098.

[92] Churchill BM, Aliabadi H, landau EH, et al: Ureteral bladder augmentation. J Urol 1993. 150 (2 pt 2): 716-720.

[93] Bellinger MF: Urelerocystoplasty update. World J Urol 1998: 16 (4): 251-254.

[94] Landau EH, Jayanthi VR, Khoury AE, et al: Bladder agumentation: Ureterocystoplasty versus ilcocystoplasty. J Urol 1994: 152 (2 pt 2): 716-719.

[95] Hitchcock RJ, Duffy PG, Malone PW: Ureterocystoplasty: The bladder augmentation of choice. Br J Urol 1994: 73(5):575-579.

[96] Ben-Chaim J, Partin AW, Jeffs RD: Ureteral bladder augmentation using the lower pole ureter of a duplicated system. Urol 1996: 47 (1): 135-137.

[97] Ahmed S, Neel KF, Sen S: Tandem Ureterocystoplasty. Aust N Z J Surg 1998: 68(3): 203-205.

[98] Lailas NG, Cilento B, Atala A: Progressive ureteral dilation for subsequent ureterocystoplasty. J Urol 1996: 156 (3): 1151-1153.

[99] Ikeguchi EF, Stifelman MD, Hensle IW: Ureteral tissue expansion for bladder augmentation. J Urol 1998: 159 (5): 1665-1668.

[100] Satar N, Yoo J, Atala A: Progressive bladder dilation for subsequent augmentation cystoplasty. J Urol 1999: 162: 829-831.

[101] Atala A: New methods of bladder augmentation. BJU international (2000), 85, suppl. 3, 24-34.

[102] Kim BS, Mooney DK: Development of biocompatible synthetic extracellular matrices for tissue engineering. Trends Biotechnol 1998: 16:224-230.

[103] Atala A: Future perspectives in reconstructive surgery using tissue engineering. Urol Clin North Am 1999; 26:157-165, ix-x.

[104] Atala A: Autologous cell transplantation for urologic reconstruction. J Urol 1998; 159: 2.

[105] Pariente JL, Kim BS, Atala A: In vitro biocompatibility assessment of naturally derived and synthetic biomaterials using normal human urothelial cells. J Biomed Mater Res 2001: 55: 33-39.

[106] Fishman U, flores En, Scott B, et al: Use of fresh placental membranes for bladder reconstruction. J Urol 1987: 138: 1291. 
[107] Kambic H, Kay R, Chen JF, et al: Biodegradable pericardial implants for bladder augmentation: a 2.5 year study in dogs. J Urol 1992; 539-543.

[108] Scott R, Mohammed R, Gorham SD, et al: The evolution of a biodegradable membrane for use in urological surgery: A summary of 109 in vivo experiments. Br J Urol 1988: 62(1): 26-31.

[109] Kropp BP: Small-intestinal submucosa for bladder augmentation. A review of preclinical studies. World J Urol 1998: 16 (4): 262-267.

[110] Kropp BR, Rippy MK, Badylak SF, et al: Regenerative urinary bladder augmentation using small intestinal submucosa: Urodynamic and histopathologic assessment in long-term canine bladder augmentations. J Urol 1996: 155 (6): 2098-2104.

[111] Piechota HJ, Dahms SE, Nunes LS, et al: In vitro functional properties of the rat bladder regenerated by the bladder acellular matrix graft. J Urol 1998: 159(5): 17171724.

[112] Probst M, Dahiya R, Garrier S, tanagho EA: Reproduction of functional smooth muscle tissue and partial bladder replacement. Br J Urol 1997; 79: 505-515.

[113] Yoo JJ, Men J, Oberpenning F: A bladder augmentation using allogenic bladder submucosal seeded with cells. Urol 1998: 51(2): 221-225.

[114] Atala A, Vacanti JP, Peters CA, et al: Formation of urothelial structures in vivo from dissociated cells attached to biodegradable polymer scaffolds in vitro. J Urol 1992b; 148:658.

[115] Atala A, Freeman MR, Vacanti JP, et al: Implantation in vivo and retrieval of artificial structures consisting of rabbit and human urothelium and human bladder muscle. J Urol 1993b; 150:608-612.

[116] Oberpenning F. Meng J, Yoo JJ, et al: De novo reconstitution of a functional mammalian urinary bladder by tissue engineering [see comments]. Nat Biotechnol 1999; 17(2): 149-155.

[117] Rackley RR, Abdelmalak JB: Laparoscopic augmentation cystoplasty: surgical technique; Urol Clin Nor Am (2001); 28 (3): 663.

[118] Gill IS, Rackley RR, Merancy AM, et al.: Laparoscopic enterocystoplasty. Urology (2000); 55(2): $178-81$.

[119] Elliolt SP, Meng MV, Anwar HP, et al.: Complete laparoscopic ileal cystoplasty. Urology (2002); 59(6): $939-43$.

[120] Hedican SP, Schulam PG, Docimo SG (1999): Laparoscopic assisted reconstructive surgery: J Urol 161(1): 267- 270.

[121] Ehrlich RM, Gershman A (1993): Laparoscopic seromyotomy (auto-augmentation) for non-neurogenic neurogenic bladder in a child: initial case report. Urology 42(2): $175-178$.

[122] McDougall EM, Clayman RV, Figenshau RS, Pearle MS (1995): Laparoscopic Retropubic autoaugmentation of the bladder. J Urol 153: 123- 126.

[123] Baren V, Bishop MR: Laparosopic bladder autoaugmentation in children. Urol. Clin. N. Am. (1998); 25 (3): 533 - 40. 


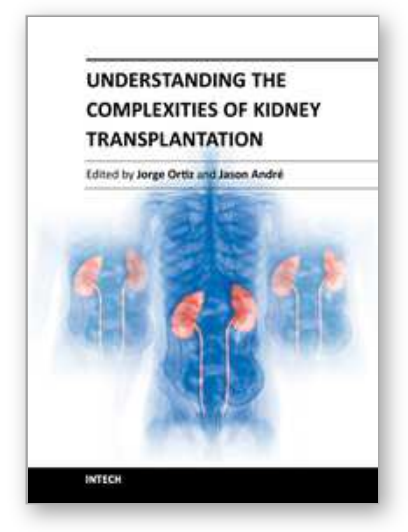

\author{
Understanding the Complexities of Kidney Transplantation \\ Edited by Prof. Jorge Ortiz
}

ISBN 978-953-307-819-9

Hard cover, 564 pages

Publisher InTech

Published online 06, September, 2011

Published in print edition September, 2011

Kidney transplantation is a complex field that incorporates several different specialties to manage the transplant patient. This book was created because of the importance of kidney transplantation. This volume focuses on the complexities of the transplant patient. In particular, there is a focus on the comorbidities and special considerations for a transplant patient and how they affect kidney transplant outcomes. Contributors to this book are from all over the world and are experts in their individual fields. They were all individually approached to add a chapter to this book and with their efforts this book was formed. Understanding the Complexities of Kidney Transplantation gives the reader an excellent foundation to build upon to truly understand kidney transplantation.

\title{
How to reference
}

In order to correctly reference this scholarly work, feel free to copy and paste the following:

Ashraf Abou-Elela (2011). Augmentation Cystoplasty: in Pretransplant Recepients, Understanding the Complexities of Kidney Transplantation, Prof. Jorge Ortiz (Ed.), ISBN: 978-953-307-819-9, InTech, Available from: http://www.intechopen.com/books/understanding-the-complexities-of-kidneytransplantation/augmentation-cystoplasty-in-pretransplant-recepients

\section{INTECH}

open science | open minds

\section{InTech Europe}

University Campus STeP Ri

Slavka Krautzeka 83/A

51000 Rijeka, Croatia

Phone: +385 (51) 770447

Fax: +385 (51) 686166

www.intechopen.com

\section{InTech China}

Unit 405, Office Block, Hotel Equatorial Shanghai

No.65, Yan An Road (West), Shanghai, 200040, China

中国上海市延安西路65号上海国际贵都大饭店办公楼 405 单元

Phone: +86-21-62489820

Fax: $+86-21-62489821$ 
(C) 2011 The Author(s). Licensee IntechOpen. This chapter is distributed under the terms of the Creative Commons Attribution-NonCommercialShareAlike-3.0 License, which permits use, distribution and reproduction for non-commercial purposes, provided the original is properly cited and derivative works building on this content are distributed under the same license. 